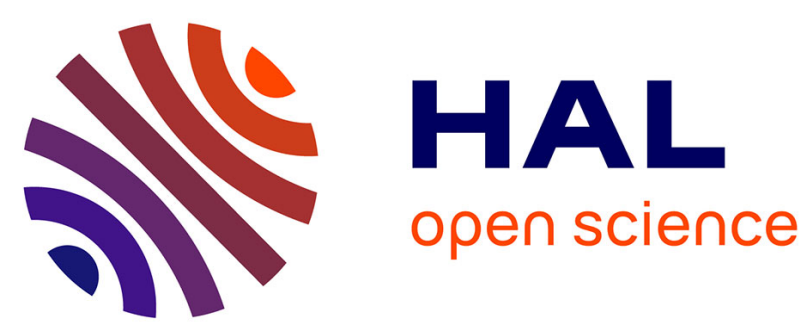

\title{
The viral restriction factor tetherin/BST2 tethers cytokinetic midbody remnants to the cell surface
}

Adrien Presle, Stéphane Frémont, Audrey Salles, Pierre-Henri Commere,

Nathalie Sassoon, Clarisse Berlioz-Torrent, Neetu Gupta-Rossi, Arnaud Echard

\section{To cite this version:}

Adrien Presle, Stéphane Frémont, Audrey Salles, Pierre-Henri Commere, Nathalie Sassoon, et al.. The viral restriction factor tetherin/BST2 tethers cytokinetic midbody remnants to the cell surface. Current Biology - CB, 2021, 31 (10), pp.2203-2213.e5. 10.1016/j.cub.2021.02.039 • pasteur-03254539

\section{HAL Id: pasteur-03254539}

https://hal-pasteur.archives-ouvertes.fr/pasteur-03254539

Submitted on 15 Jun 2021

HAL is a multi-disciplinary open access archive for the deposit and dissemination of scientific research documents, whether they are published or not. The documents may come from teaching and research institutions in France or abroad, or from public or private research centers.
L'archive ouverte pluridisciplinaire HAL, est destinée au dépôt et à la diffusion de documents scientifiques de niveau recherche, publiés ou non, émanant des établissements d'enseignement et de recherche français ou étrangers, des laboratoires publics ou privés.

\section{(ㄷ)(1) $\$$}

Distributed under a Creative Commons Attribution - NonCommerciall 4.0 International 


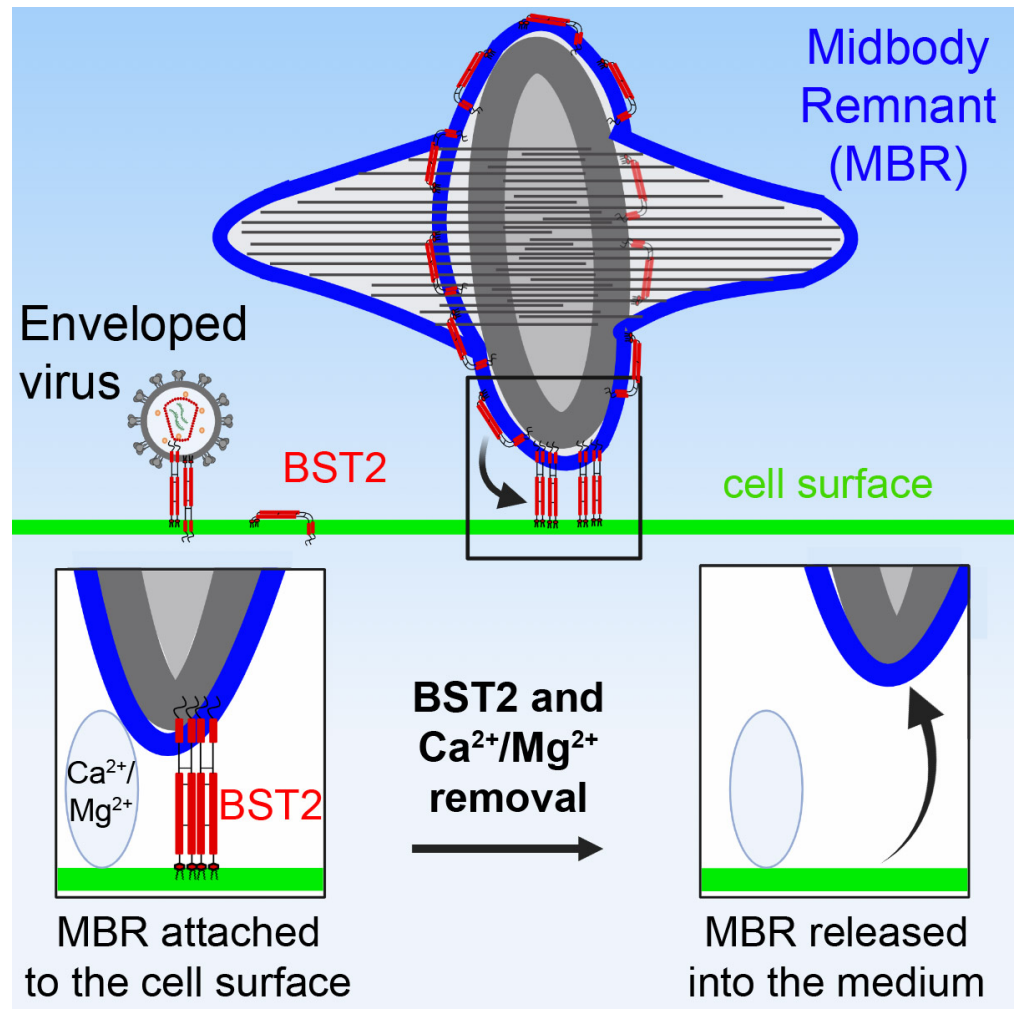




\section{The Viral Restriction Factor Tetherin / BST2 \\ Tethers Cytokinetic Midbody Remnants \\ to the Cell Surface}

Adrien Presle ${ }^{1,2}$, Stéphane Frémont ${ }^{1}$, Audrey Salles ${ }^{3}$, Pierre-Henri Commere ${ }^{4}$, Nathalie Sassoon ${ }^{1}$, Clarisse Berlioz-Torrent ${ }^{5}$, Neetu Gupta-Rossi ${ }^{1, \#}$ and Arnaud Echard ${ }^{1,6, \#, *}$

${ }^{1}$ Traffic and Cell Division Lab, Institut Pasteur, UMR3691, CNRS, 25-28 rue du Dr Roux, F75015 Paris, France

${ }^{2}$ Sorbonne Université, Collège doctoral, F-75005 Paris, France

${ }^{3}$ UTechS Photonic Biolmaging PBI (Imagopole), Centre de Recherche et de Ressources

Technologiques C2RT, Institut Pasteur, F-75015 Paris, France

${ }^{4}$ UTechS CB, Centre de Recherche et de Ressources Technologiques C2RT, Institut Pasteur, F75015 Paris, France

${ }^{5}$ Université de Paris, Institut Cochin, INSERM, CNRS, F-75014 Paris, France

${ }^{6}$ Lead Contact

"Equal contribution

${ }^{*}$ Correspondence: arnaud.echard@pasteur.fr 
The midbody at the center of the intercellular bridge connecting dividing cells recruits the machinery essential for the final steps of cytokinesis ${ }^{1-5}$. Successive abscission on both sides of the midbody generates a free midbody remnant (MBR) that can be inherited and accumulated in many cancer, immortalized and stem cells, both in culture and in vivo ${ }^{6-12}$. Strikingly, this organelle was recently shown to contain information that induces cancer cell proliferation, influences cell polarity and promotes dorso-ventral axis specification upon interaction with recipient cells ${ }^{13-16}$. Yet, the mechanisms by which the MBR is captured by either a daughter cell or a distant cell are poorly described ${ }^{10,14}$. Here, we report that BST2/Tetherin, a wellestablished restriction factor that blocks the release of numerous enveloped viruses from the surface of infected cells ${ }^{17-20}$, plays an analogous role in retaining midbody remnants. We found that BST2 is enriched at the midbody during cytokinesis and localizes at the surface of MBRs in a variety of cells. Knocking-out BST2 induces the detachment of MBRs from the cell surface, their accumulation in the extracellular medium and their transfer to distant cells. Mechanistically, the localization of BST2 at the MBR membrane is both necessary and sufficient for the interaction between MBRs and the cell surface. We thus propose that BST2 tethers post-cytokinetic midbody remnants to the cell surface. This finding reveals new parallels between cytokinesis and viral biology ${ }^{21-26}$ that unexpectedly extend beyond the ESCRT-dependent abscission step. 


\section{RESULTS AND DISCUSSION}

\section{BST2 is enriched at the midbody during cytokinesis and localizes to the surface of MBRs}

In most cell types, midbody remnants (MBRs) are either released into the extracellular medium or interact with the surface of a recipient cell, usually one of the two daughter cells, before being engulfed and degraded 6 , 7, 9, 10, 12, 14, 27-33 (Figure S1A). While integrins partially account for the attachment of purified $\mathrm{MBRs}^{14}$, understanding how MBRs are captured and retained remains a key question, since MBRs can influence cell fate and promote cell proliferation ${ }^{7,14,34}$. Recently, we achieved the purification of intact MBRs from HeLa cells and reported the quantitative proteome of this organelle that we termed Flemmingsome ${ }^{35}$. Looking back on the results, we were intrigued to identify BST2/CD317/Tetherin as a protein 3.6-fold enriched in MBRs, as compared to the total cell fraction. BST2 is a single-pass transmembrane protein with a GPI anchor that physically tethers numerous enveloped viruses to the surface of infected cells. BST2/Tetherin thereby restricts viral propagation ${ }^{17,} 18,36-43$ (Figure 1A). More recently, BST2 was shown to retain exosomes at the plasma membrane ${ }^{44}$, revealing a tethering function of BST2 in non-infected cells. We therefore reasoned that BST2 might play a role in retaining MBRs at the cell surface (Figure 1A).

To investigate whether BST2 functions in MBR anchoring, we first characterized its localization in fixed samples. In addition to BST2 being present at the cell surface, immunofluorescence in HeLa cells labelled with the midbody marker CEP55 revealed that 94\% of midbodies (present at the center of cytokinetic intercellular bridges, $n=100$ ) and $98 \%$ of MBRs (present at the surface of individual cells, $n=100$ ) were positive for BST2 (Figures 1B and $1 \mathrm{C}$ ). Super-resolution microscopy using structured illumination (SIM) revealed that BST2 localized in a ring-like pattern at the outer rim of the MBR, wrapping around CEP55, suggesting that BST2 resided at the MBR surface (Figure 1D). To confirm this, we purified intact, EDTA- 
detached MBRs from HeLa cells that stably express the midbody marker GFP-MKLP1 ${ }^{45}$ using flow cytometry, as described previously (GFP+ MBRs, Figure S1B and ref. ${ }^{35}$ ) and stained them without permeabilization with anti-BST2 antibodies (Figure 1E). We found that $99 \%$ of purified MBRs $(n=100)$ were positive for BST2, demonstrating that BST2 indeed localizes at the plasma membrane surrounding the MBR. Finally, using time-lapse fluorescent microscopy of HeLa cells that expressed GFP-tagged BST2, we observed that BST2 accumulated at the midbody soon after furrow ingression and persisted after abscission, explaining BST2 presence on MBRs (Figure 1F and Video S1).

BST2 is constitutively expressed in many human cell types and can be strongly induced upon cytokine stimulation like interferon- $\alpha$ (IFN- $\alpha)^{17,18,46-48}$. BST2 was constitutively found both at the midbody and the MBR in the cancer cells that we examined, such as the Caco-2 colon cancer cells (Figure 1G), the HepG2 hepatocellular carcinoma and the SK-MEL2 melanoma cells (Figure S1C). This was also the case in primary cells like human T lymphocytes and HUVEC endothelial cells (Figure S1C). In the HEK 293 immortalized kidney cells in which BST2 was undetectable, treatment with IFN- $\alpha$ strongly induced BST2 expression and localization, both at the midbody and the MBRs (Figure $\mathbf{1 H}$ ). Altogether, we conclude that BST2 localizes at the MBR in a variety of cancer and primary cells, either constitutively or upon induction.

\section{BST2 promotes MBR retention at the cell surface}

Since BST2 is a well-characterized tether for enveloped viruses and localizes at the surface of MBRs, we next investigated whether this protein could favor the retention of MBRs at the cell surface. Thanks to CRISPR/Cas9 technology, we established a BST2 knock out (BST2 KO) HeLa cell line that stably expressed the MBR marker GFP-MKLP1. We selected a clone in 
which the BST2 protein expression was abolished, as shown by western blot (Figure 2A). This resulted from two insertion/deletion events at the genomic level, leading to a translational frameshift and a premature STOP codon in the transcript (Figures S2A and S2B). As expected, BST2 signal was lost from MBRs (Figure 2B), confirming the specificity of our BST2 staining. Importantly, when comparing BST2 KO cells with control KO cells (CTRL KO), we did not observe any differences in their cell cycle (Figure S2C), in the number of cells undergoing cytokinesis (Figure S2D) or in the number of cells that successfully completed abscission (Figure S2E). Thus, BST2 KO did not change the rate of MBR production. We next compared the number of MBRs found at the cell surface in control and BST2 KO conditions. To unequivocally discriminate between internalized versus cell surface-localized MBRs, we carried out surface staining for CD81 and CD9P1 transmembrane proteins. Indeed, our recent proteomic study revealed the enrichment of several tetraspanins and associated proteins in $\mathrm{MBRs}^{35}$ and we now took advantage of antibodies against the extracellular domains of CD81 or CD9P149, 50 to reliably label non-permeabilized, purified MBRs (Figures S2F and S2G). Remarkably, surface staining of MBRs with CD81 (Figure 2C) or CD9P1 (Figure S2H) revealed a decrease in the number of MBRs at the cell surface after BST2 KO. These data suggest that, in the absence of BST2, MBRs are not properly retained at the cell surface and are likely released into the extracellular medium.

We then quantified, by flow cytometry, the amount of MBRs in the extracellular medium released from GFP-MKLP1 control KO and BST2 KO HeLa cells and observed a twofold increase upon BST2 KO (Figure 2D). As described for virions ${ }^{17,}{ }^{18}$, we hypothesized that the release of MBRs into the medium upon BST2 KO would promote long-range transfer to distant cells within the population. To test this idea, we used co-culture experiments using control KO or BST2 KO HeLa cells expressing GFP-MKLP1 (which labels nuclei, midbodies and 
MBRs) as donor cells and non-fluorescent WT HeLa cells as recipients (Figure 2E, left). Importantly, when compared to control co-cultures where BST2 was expressed both on donor and recipient cells, we found that BST2 KO MBRs (GFP-labelled) were twice as frequently transferred onto WT recipient cells (Figure $\mathbf{2 E}$, middle and right). We therefore conclude that BST2 prevents MBR release into the extracellular medium and their long-range transfer between cells.

\section{GPI-anchoring is required for MBR retention by BST2}

To further understand how BST2 controls MBR retention, we turned to time-lapse microscopy and followed the fate of single GFP-MKLP1-labelled MBRs in control and BST2 KO cells. In control cells, most of the MBRs generated after abscission were retained and roamed over the cell surface of one of the two daughter cells, before being engulfed, as previously described (ref. ${ }^{10}$ and Figures S1A and 3A). The GFP-MKLP1 signal at the MBR initially remained constant both at the cell surface and right after internalization (Figure $\mathbf{3 A}$, time 0 min - 570 min). Then, the GFP-MKLP1 fluorescence progressively disappeared over 2 hours (Figure 3A, time $585 \mathrm{~min}-705 \mathrm{~min})$, due to quenching in the acidic, degradative environment of late endosomes/lysosomes ${ }^{10}$. In rare instances however, we noticed a sudden and complete disappearance of the MKLP1-GFP signal between two successive timeframes, corroborated by the concomitant disappearance of the dark MBR-shape in phase contrast (Figure 3B, between time $750 \mathrm{~min}$ and $765 \mathrm{~min}$ ), demonstrating that the MBR had been released from the cell surface into the medium. While this sudden jump occurred in $4 \%$ of control cells, the BST2 KO cell line showed a 4-fold increase in MBR release into the extracellular medium (Figure 3C). Thus, knocking out BST2 increases the number of MBR-releasing events. This finding is 
consistent with the observed increase of MBRs in the medium (Figure 2D) as well as the reduced rate of cells with MBRs at the cell surface upon BST2 KO (Figure 2C).

It is well established that the over-expression of the HIV-1 accessory protein VPU downregulates BST2 from the cell surface and induces virion release ${ }^{17,18,51-53}$. Similarly, we observed that VPU overexpression downregulated BST2 both from the cell surface and the midbody. Again, this induced MBR release to levels identical as observed upon BST2 KO (Figure 3D).

Tethering of viruses to the cell surface via BST2 relies on its unique topology and requires the presence of the transmembrane domain together with the C-terminal GPI anchor ${ }^{37,54}$. These two domains can insert into the host plasma membrane on the one hand and the virion membrane on the other hand, thus allowing BST2 to physically tether viral particles to the infected cell (Figures $\mathbf{1 A}$ and 3E). We thus tested whether the GPI anchor requirement also applied to retain MBRs at the cell surface. First, we stably re-expressed in the BST2 KO cell line either wild-type BST2 (BST2 WT) or a mutant in which the two tyrosines (tyrosines 6 and 8 ) in the $\mathrm{N}$-terminal cytoplasmic tail were mutated to alanines (hereafter named BST2 Y2A). The latter mutant was used as a control since it fails to induce NF-KB signaling but fully retains tethering activities towards viruse ${ }^{55}$. As shown by FACS analysis, the surface expression levels of the re-introduced BST2 WT and BST2 Y2A were comparable, but lower than endogenous BST2 levels (Figure S3A). In addition, both BST2 WT and BST2 Y2A properly localized to MBRs (Figures 3F and S3B). Importantly, both MBR accumulation at the cell surface (fixed samples, Figure $\mathbf{3 G}$ ) and MBR retention (video microscopy, Figure $\mathbf{3 H}$ ) were rescued to normal levels in BST2 KO cells that re-expressed either BST2 WT or BST2 Y2A. Next, we stably expressed in the BST2 KO cell line, a BST2 mutant lacking the GPI-anchor (hereafter named BST2 delGPI), which is unable to tether virions ${ }^{37}$. Of note, BST2 delGPI and BST2 WT 
were expressed at comparable levels at the MBR (Figures $\mathbf{3 F}$ and S3B), and BST2 delGPI expression at the cell surface was higher than the endogenous BST2 and thus was not limiting (Figure S3A). However, BST2 delGPI did not rescue the defects in MBR retention at the cell surface (Figure 3G) nor the increased release, measured by time-lapse microscopy (Figure 3H) observed in the BST2 KO cells. Thus, like for viral tethering, the GPI anchor of BST2 is essential to promote MBR retention at the cell surface.

Since knocking out BST2 does not lead to the release of all MBRs (Figures 2 and 3), additional factors that promote MBR tethering to the cell surface must be involved. Recently, using the peptide cilengitide (RGDfV) which preferentially inhibits $\alpha \mathrm{V}$ chain containing integrins ${ }^{14,56}$, the $\alpha \mathrm{V} \beta 3$ and/or $\alpha \mathrm{V} \beta 5$ integrins have been proposed to promote the attachment and capture of purified MBRs to the cell's surface. As expected for a peptide inhibiting integrins, RGDFV (but not the inactive peptide RADfV) impaired cell re-adhesion (Figure S4A) and induced progressive cell rounding of adherent cells (Figure S4B). Despite inhibiting integrins efficiently, RGDFV did not increase the release of endogenous MBRs already present at the cell surface during the treatment, neither from control KO nor from BST2 KO cells, as assessed by videomicroscopy (Figure 4A). This suggests that RGDfV-sensitive integrins do not cooperate with BST2 to retain endogenous MBRs. Using $\alpha \mathrm{V}$ integrin KO cells generated by CRISPR/Cas9, we confirmed that $\alpha \mathrm{V}$ deletion did not increase the release of MBRs either (Figure S4C). Interestingly, treating cells with the $\mathrm{Ca}^{2+} / \mathrm{Mg}^{2+}$ chelator EDTA and following MBRs release by videomicroscopy revealed a synergy between EDTA-sensitive factors and BST2 for tethering MBRs to the cell surface (Figure 4B). Despite the short recording due to cell detachment (3 hours), approximately 50\% of the GFP-MKLP1-positive MBRs were released upon BST2 KO when combined with EDTA treatment. Note that intracellular (internalized) GFP-MBRs cannot be released but are still fluorescent before reaching 
degradative compartments ${ }^{9,10}$. Thus, the percentage of MBRs present at the cell surface and that were released is actually underestimated in this assay. Altogether, our results indicate that BST2 is a critical tether for MBRs that cooperates with yet to be discovered, EDTAsensitive factors.

\section{BST2 localization at the MBR is required for promoting MBR attachment}

We next observed that a homodimerization mutant of BST2 lacking the three specific cysteines that stabilize the coiled-coil domain (BST2 C3A) ${ }^{37-39}$ failed to localize at the MBR (Figures 4C, S3C and S3D). Remarkably, although this mutant was expressed at the cell surface as much as BST2 WT (Figure S3C), BST2 C3A also failed to retain MBRs at the cell surface (Figure 4D), as observed for virions ${ }^{37}$. This shows the requirement of BST2 homodimerization for both its recruitment to the midbody and its tethering activity.

Experiments using BST2 KO cells (Figures 2 and 3) could not discriminate whether BST2 was required at the cell surface and/or at the MBRs to retain them, since it was depleted from both locations. To answer this question, we purified, using flow cytometry as described in ref. ${ }^{35}$, MBRs from donor GFP-MKLP1 HeLa cells expressing BST2 (CTRL KO) or not (BST2 KO). After the incubation step, we monitored the retention of purified MBRs at the surface of nonfluorescent, recipient HeLa cells that expressed or not BST2 (Figures 4E and S4D). In each combination, the same number of MBRs was incubated with the same number of recipient cells. We then quantified the release of these newly attached, GFP-labeled MBRs from the cell surface of recipient cells by time-lapse microscopy (Figure 4F). Interestingly, deposited BST2positive MBRs were retained as efficiently by recipient cells, whether the cells expressed or not BST2 at their surface. In contrast, MBRs lacking BST2 were more often released when interacting with BST2 KO cells, consistent with the data described above (Figures 2 and $\mathbf{3}$ ). 
Importantly, this increased release was not affected by BST2 expression on the recipient cell (recipient CTRL KO) (Figure 4F). We thus conclude that the localization of BST2 at the MBR membrane is necessary and sufficient to promote MBR attachment to the cell surface.

Here, we have identified the transmembrane protein BST2/Tetherin as a key factor that contributes to retain post-cytokinetic MBRs at the plasma membrane. In BST2 KO cells, the frequency of MBR detachment from the cell surface increases, MBRs accumulate in the extracellular medium and are more often transferred to distant cells (Figures $\mathbf{2}$ and $\mathbf{3}$ ). Strikingly, this mirrors what happens for virions, when enveloped viruses are able to counteract BST2 restriction ${ }^{17-20}$ and we thus propose that BST2 also acts as a protein that tethers midbody remnants to the plasma membrane. Recently, BST2 was reported to tether exosomes to the cell surface after inhibition of the V-ATPase ${ }^{44}$. To our knowledge, our data provide the first functional evidence of a BST2 tethering activity in unperturbed and uninfected cells.

How does BST2 tether MBRs to the cell surface? For virions, a few molecules of BST2 can physically tether these relatively small $(50-100 \mathrm{~nm})$ particles, by spanning the virion-cell scission site (ref. ${ }^{19}$ and Figure 1A). We cannot exclude that BST2 at the cell surface also participates in the tethering of MBRs, but testing this possibility is technically challenging as this would require to selectively inhibit the localization of WT BST2 at the MBR but not at the cell surface. However, tethering between free MBRs and the plasma membrane was observed and requires that BST2 localizes at the MBR side but not at the interacting cell side (Figures 4E and 4F). As for viral and exosomal tethering ${ }^{44}$, MBR tethering absolutely depends on BST2's terminal GPI anchor since BST2 delGPI (re-expressed at the MBR as much as BST2 WT, Figure S3B) failed to rescue MBR tethering (Figures $\mathbf{3 G}$ and $\mathbf{3 H}$ ). We thus propose that the GPI 
moiety, initially inserted in the outer leaflet of the MBR's plasma membrane, can flip and insert into the plasma membrane of the facing recipient cell once both membranes are close enough (Figure 4G left). Such transfer of a GPI moiety between membranes has been observed for a variety of GPI-anchored proteins, both in vivo and in vitro ${ }^{57,58}$. At the surface of HIV-1 infected cells, BST2 is incorporated into HIV-1 particles as a parallel homodimer with its GPI anchor preferentially inserted into the virion. However, in order to tether several virions together, the transmembrane domain can also be inserted in the virions ${ }^{41}$. Although the final topology is similar for virion and MBR tethering (with the transmembrane domain and GPI anchor in opposite membranes, Figure $3 \mathrm{E}$ ), the mechanism proposed for MBR tethering by BST2 is original. This unusual tethering might reflect the fact that, contrary to virions, MBRs are first, large particles (typically $2000 \times 1500 \mathrm{~nm}$ ) and second, highly enriched for BST2 molecules (Figure 1). Besides this direct MBR tethering activity via BST2, it is possible that BST2, at the MBR and/or at the cell surface, interacts with partners or locally organizes membrane microdomains (see below) ${ }^{59}$, that also contribute to the MBR-cell attachment.

The tethering activity of BST2 raises the question of how it is localized to the MBR. BST2 localization at or close to the viral budding site depends on its GPI anchor where it interacts with cholesterol and PtdIns(4,5)P2-rich lipid domains ${ }^{54,60}$. We observed that the GPI moiety is also an important determinant for BST2 localization at the MBR: while expressed more than BST2 WT at the cell surface, BST2 delGPI localized proportionally less than BST2 WT to the midbody/MBR (Figures S3A and S3B). Interestingly, quantitative lipidomics previously demonstrated that midbodies have a very peculiar, raft-like composition rich in cholesterol, PtdIns(4,5)P2 and sphingolipids ${ }^{61}$. This suggests that the determinants of BST2 localization at viral budding sites and at MBRs are highly dependent on the local lipid composition of the membrane. 
BST2 is the first protein whose depletion impairs MBR retention at the cell surface. However, not all MBRs are released in the absence of BST2. This is also true for exosomes: a fraction of exosomes is still retained at the cell surface upon BST2 $\mathrm{KO}^{44}$. Thus, multiple, redundant molecular machineries appear to tether MBRs to the cell surface. At the molecular level, the complete release of an MBR implies the simultaneous detachment of all the links between this organelle and the plasma membrane. Interestingly, our data highlight that BST2 synergizes with EDTA-sensitive factors to retain MBRs at the cell surface (Figures $\mathbf{4 B}$ and $\mathbf{4 G}$ right). Identifying the $\mathrm{Ca}^{2+} / \mathrm{Mg}^{2+}$-dependent factors (lipids or proteins) will be an important next step.

MBRs contain information that promotes cell proliferation once captured and internalized in cultured cells ${ }^{14}$. We noticed that knocking out BST2 was not sufficient to significantly decrease progression in the cell cycle (Figure S2C), expression of the proliferation marker Ki67 (Figure S4E) or long-term proliferation in clonogenic assays (Figure S4F). This could be due to the fact that not all MBRs are released upon BST2 KO (Figure 2). Of note, we observed that MBRs tend to accumulate intracellularly once internalized in BST2 KO cells (Figure S4G), indicating a role for BST2 in the turnover/degradation of MBRs beyond tethering. Interestingly, the intracellular MBRs were more often present in Lamp1-negative (Lamp1') compartments (Figure S4G right), where they have been recently proposed to signal for proliferation ${ }^{14}$. This could also explain why, despite the increase in MBR release from cells (Figure 2C), BST2 KO does not impact on overall cell proliferation. The physiological relevance of MBR tethering by BST2 thus remains to be explored, in particular in vivo. Since BST2 KO mice are viable ${ }^{42}$ we suspect that putative signaling functions of MBRs in mammals would become apparent when $\mathrm{BST} 2$ and the $\mathrm{Ca}^{2+} / \mathrm{Mg}^{2+}$-dependent factors are simultaneously eliminated. Alternatively, the function of BST2-dependent MBR tethering might be important 
only in specific cell types (such as during the development of the brain, where MBRs accumulate at specific stages ${ }^{6}$ ) or in pathological conditions (such as in tumor cells, where BST2 is frequently found up-regulated ${ }^{62,63}$ ).

Altogether, we identified a striking common function of BST2 in retaining virions and MBRs at the plasma membrane. In both cases, BST2/Tetherin limits their release into the extracellular medium and their spread to distant cells. Thus, beyond the ESCRT-dependent membrane scission events, our work reveals a novel and unexpected parallel between viral biology and cytokinesis. 


\section{ACKNOWLEDGMENTS}

We thank R. Basto, N. Casartelli, T. Advedissian, R. Shaughnessy, O. Schwartz, M. Serres for critical reading of the manuscript; the Echard Lab members for helpful discussions; the Recombinant antibodies platform (TAb-IP, Institut Curie, Paris) and Eric Rubinstein (Centre d'Immunologie et des Maladies Infectieuses, CIMI-Paris) for antibodies, N. Casartelli, O. Schwartz, M. Lecuit, E. Lemichez (Institut Pasteur), M. Piel (Institut Curie) and the Hyman Lab (MPI-MCBG Dresden) for cells, K. Janvier (Institut Cochin) for the pcDNA3 BST2 and BST2-GFP plasmids. We thank S. Lebreton (Zurzolo Lab, Institut Pasteur) and Jean-Yves Tinevez (Image Analysis Hub, Institut Pasteur) for experimental advice and help in quantifications, the Pasteur photo service for imaging. UTechS PBI is part of the France-Biolmaging infrastructure network (FBI) supported by the French National Research Agency (ANR-10-INSB-04; Investments for the Future), and acknowledges support from ANR/FBI and the Région lle-de-France (program "Domaine d'Intérêt Majeur-Malinf") for the use of the Zeiss LSM 780 Elyra PS1 microscope. We thank S. Schmutz from the Center for Translational Science (CRT)-Cytometry and Biomarkers Utechs, Institut Pasteur. This work has been supported by Institut Pasteur, CNRS, and ANR (AbsCystem, Cytosign, RabEndoCilio) to A.E.. A.P. received a fellowship from the Doctoral School Complexité du Vivant ED515, contrat $n^{\circ} 2611$ bis/2016 and Fondation ARC pour la recherche sur le cancer (DOC20190508876).

\section{AUTHOR CONTRIBUTIONS}

A.P. carried out and analyzed all the experiments except mentioned otherwise. S.F. carried out and analyzed the experiments in Figures $2 \mathrm{C}, 3 \mathrm{G}, \mathrm{S} 2 \mathrm{~F}, \mathrm{~S} 2 \mathrm{G}, \mathrm{S} 2 \mathrm{H}$ and S4G; A.P. and N.G-R. in S1C; N.G-R. and PH.C. in S2C and S4E; N.G-R. and N.S. in S4F, and A.S., N. G-R and A.P. in Figure 1D. C.B.T. provided reagents and helpful discussions. A.E. secured funding. N.G-R. and A.E. analyzed and supervised the work. A.E, N.G-R., S.F. and A.P. wrote the manuscript with the help of C.B.T.

\section{DECLARATION OF INTERESTS}

The authors declare no competing interests. 
MAIN FIGURE LEGENDS

Figure 1. BST2 is enriched at the midbody during cytokinesis and localizes to the surface of MBRs.

(A) Scheme representing an enveloped virus, an exosome and the hypothesis of a MBR being tethered by BST2. Blow-up: BST2 topology in the context of virus/exosome anchoring. See Figure S1A for MBR generation and fate.

(B) Endogenous localization of BST2 at the midbody in an intercellular bridge (Midbody, upper panel) and a MBR (lower panel) in HeLa cells, co-stained for acetylated tubulin (ac-tub), DAPI and CEP55. Scale bar $10 \mu \mathrm{m}$.

(C) Quantification of BST2-positive intercellular bridge midbodies and MBRs (mean \pm SD) in HeLa cells. $N=3$ independent experiments, $n=100$ midbodies or MBRs per experiment.

(D) MBR imaged by Structured Illumination Microscopy for endogenous BST2 and CEP55 in HeLa cells. Scale bar $10 \mu \mathrm{m}$.

(E) Purified GFP-MKLP1 MBR sorted by flow cytometry and stained for the extracellular domain of endogenous BST2. Scale bar $2 \mu \mathrm{m}$. See Figure S1B for MBR purification.

(F) Snapshots of time-lapse spinning-disk confocal microscopy video of BST2-GFP during HeLa cell cytokinesis (insets: BST2 in grey). SiR-Tubulin labels the intercellular bridge and the MBR. Brackets and arrowheads mark the bridge and the MBR, respectively. Scale bar $10 \mu \mathrm{m}$. See Video S1.

(G) Endogenous localization of BST2 at the midbody in an intercellular bridge (Midbody) and a MBR in Caco-2 cells, stained for acetylated-tubulin (ac-tub), DAPI and CEP55. Scale bars 10 $\mu \mathrm{m}$.

(H) Left: Western blots of lysates from HEK 293 cells treated or not with IFNa, revealed as indicated. Loading control: GAPDH. Asterisks indicate BST2 glycosylated monomers $\left({ }^{*}\right)$ and dimers (**). Right: Endogenous localization of BST2 at the Midbody and MBR in HEK 293 cells treated or not with IFNa, stained for acetylated-tubulin (ac-tub), DAPI and CEP55. Scale bars $10 \mu \mathrm{m}$. See Figure S1C for BST2 localization in additional cell types. 
Figure 2. BST2 promotes MBR retention at the cell surface.

(A) Western blot of deglycosylated lysates from CTRL KO or BST2 KO GFP-MKLP1 HeLa cells. Loading control: GAPDH. Asterisks indicate BST2 deglycosylated monomers $\left({ }^{*}\right)$ and dimers $\left({ }^{* *}\right)$. See Figures S2A, S2B, S2C, S2D, S2E and Table S1 for BST2 KO cell characterization.

(B) Endogenous BST2 staining of CTRL KO and BST2 KO GFP-MKLP1 cells. Arrowheads mark MBRs. Scale bars $10 \mu \mathrm{m}$.

(C) Left: CD81 surface staining of CTRL KO and BST2 KO GFP-MKLP1 cells. Arrowheads mark MBRs. Scale bars $10 \mu \mathrm{m}$. Right: percentage of MBRs at the cell surface (CD81-positive) (mean \pm SD). $N=4$ independent experiments, $n=470-533$ MBRs. Paired two-sided Student's $t$-test. See Figures S2F, S2G and S2H for additional MBR markers.

(D) Cell culture media were collected from CTRL KO and BST2 KO GFP-MKLP1 cells. MBRs were quantified by FACS with fluorescent beads and normalized with the number of cells and volume for each condition (a.u. arbitrary units). $N=3$ experiments, $n=667-3783$ MBRs per experiment. Paired two-sided Student's $t$-test.

(E) Left: Co-culture experimental set-up scheme with non-fluorescent and GFP-MKLP1 cells. GFP-MKLP1 localizes in nuclei, midbodies and MBRs. A GFP-positive MBR transferred onto a non-fluorescent cell is arrowed. Middle: Representative image of co-culture with nonfluorescent CTRL and GFP-MKLP1 BST2 KO HeLa cells, stained for BST2. A GFP-MKLP1 MBR transferred on a CTRL cell is arrowed, and an arrowhead marks a GFP-MKLP1 MBR on a GFPMKLP1 cell. Note the loss of BST2 staining in the GFP-MKLP1 BST2 KO cells (marked by stars). Right: Percentage of GFP-MKLP1 MBRs from either CTRL or BST2 KO HeLa cells transferred onto non-fluorescent CTRL HeLa cells. $N=3$ experiments, $n=1000$ MBRs per experiment. Paired two-sided Student's $t$-test. Scale bar $10 \mu \mathrm{m}$. 
Figure 3. GPI-anchoring is required for MBR retention by BST2.

(A-B) GFP-MKLP1 CTRL KO HeLa cells were imaged every $15 \mathrm{~min}$ and the midbody followed from anaphase until its degradation ( $A$, gradual loss of the GFP signal, insets) or release in the culture medium ( $B$, sudden loss of the GFP signal, insets). Brackets and arrowheads mark the intercellular bridge and the MBR, respectively. Scale bars $10 \mu \mathrm{m}$.

(C) Percentage of MBRs released in the media determined by time-lapse fluorescent microscopy (as in B), for either CTRL KO or BST2 KO cells (mean \pm SD). $N=3$ independent experiments, $n=50-100$ MBRs per experiment. Paired two-sided Student's $t$-test.

(D) Left: Endogenous labelling of BST2 at the MBR (arrowhead) in CTRL KO and BST2 KO GFPMKLP1 HeLa cells transiently transfected with plasmids encoding mCherry alone ("empty") or Vpu + mCherry. Scale bars $10 \mu \mathrm{m}$. Right: Percentage of MBRs released in the media determined by time-lapse fluorescent microscopy for CTRL KO and BST2 KO cells with or without Vpu (mean \pm SD). $N=3$ independent experiments, $n=36-50$ MBRs per experiment. Paired two-sided Student's t-test.

(E) BST2 structure and domains. The transmembrane Domain (TMD), GPI anchor, key Tyrosines (Y6, Y8) and Cysteines (C53, C61, C91) are indicated.

(F) Surface staining of BST2 (green, grey insets) in CTRL KO and BST2 KO GFP-MKLP1 HeLa cells, stably re-expressing BST2 WT, BST2 Y2A or BST2 delGPI. Arrowheads mark MBRs. Scale bars $10 \mu \mathrm{m}$. See Figures S3A and S3B for quantifications of BST2 levels at the MBR and cell surface. (G) Proportion of surface (CD81-positive) versus total (MKLP1-positive) MBRs for each cell population indicated (mean \pm SD). $N=3$ independent experiments, $n=415-461 \mathrm{MBRs}$. Paired two-sided Student's $t$-tests.

(H) Percentage of MBRs released in the media determined by time-lapse fluorescent microscopy for the indicated cell population (mean \pm SD). $N=3$ independent experiments, $n$ = 50 MBRs per experiment. Paired two-sided Student's $t$-tests. 
Figure 4. BST2 localization at the MBR is required for promoting MBR attachment.

(A) Percentage of MBRs released within 6 hours in the media determined by time-lapse fluorescent microscopy in CTRL KO or BST2 KO cells, treated or not with either RADfV or RGDFV (mean $\pm \mathrm{SD}$ ). $N=3$ independent experiments, $n=61-113$ MBRs per experiment. Paired twosided Student's $t$-tests. Note that the release of MBRs upon BST2 KO alone is quantitatively less than in Figure $3 \mathrm{C}$ since the experiment was carried out on a shorter time frame (6h), due to cell detachment in the RGDfV condition. See Figures S4A, S4B and S4C for additional characterization.

(B) Percentage of MBRs released within 3 hours in the media determined by time-lapse fluorescent microscopy in CTRL KO or BST2 KO cells, treated or not with EDTA (mean \pm SD). $N$ = 3 independent experiments, $n=150-212$ MBRs per experiment. Paired two-sided Student's $t$-tests. Note that the release of MBRs upon BST2 KO alone is quantitatively less than in Figure 3C, since the experiment was carried out on shorter time frame (3h) due to cell detachment in the EDTA condition.

(C) Surface staining of BST2 in CTRL KO, BST2 KO and BST2 KO GFP-MKLP1 HeLa cells stably expressing BST2 C3A mutant. Arrowheads mark MBRs. Scale bars $10 \mu \mathrm{m}$. See Figures S3C and S3D for quantifications of BST2 levels at the MBR and cell surface.

(D) Left panels: Percentage of MBRs at the cell surface (CD81 surface labelling) in the indicated cells (mean \pm SD). $N=3$ independent experiments, $n \geq 400$ MBRs. Paired two-sided Student's $t$-tests. CTRL KO, BST2 KO and BST2 KO + BST2 WT are from the same experiment as in Figure 3G. Right panels: Percentage of MBRs released in the media determined by time-lapse fluorescent microscopy for the indicated cells (mean \pm SD). $N=3$ independent experiments, $n$ $\geq 50$ MBRs. Paired two-sided Student's $t$-tests.

(E) Experimental setup. MBRs purified from donor GFP-MKLP1 HeLa cells (CTRL KO or BST2 KO) were incubated on non-fluorescent recipient HeLa cells (CTRL KO or BST2 KO). MBR release was assessed by time-lapse fluorescent microscopy. See Figure S4D for pictures. (F) Percentage of MBRs released in the media determined by time-lapse fluorescent microscopy for each indicated combination (mean \pm SD). $N=3$ independent experiments, $n=100 \mathrm{MBRs}$ per experiment. Paired two-sided Student's $t$-tests. See Figures S4E, S4F and S4G for additional phenotypes associated with BST2 KO. 
(G) Model for MBR-tethering by BST2. BST2 dimers present at the MBR transfer their GPIanchor to the plasma membrane of the recipient cell and enable MBR-tethering to the recipient cell. Removal of both $\mathrm{BST} 2$ and $\mathrm{Ca}^{2+} / \mathrm{Mg}^{2+}$ leads to $\mathrm{MBR}$ release. 
STAR METHODS

RESOURCE AVAILABILITY

\section{Lead Contact}

Information and requests for resources and reagents should be directed to and will be fulfilled by the Lead Contact, Arnaud Echard (arnaud.echard@pasteur.fr).

\section{Materials Availability}

Plasmids and cell lines generated in this study can be obtained through the Lead Contact.

\section{Data and Code Availability}

This study did not generate any unique datasets or code.

\section{EXPERIMENTAL MODEL AND SUBJECT DETAILS}

\section{Cell lines and cell culture}

GFP-MKLP1 HeLa and parental HeLa (female) ${ }^{45}$, HEK293 (gender not provided by ATCC), HEK293FT (female), SK-MEL2 Dynamin-GFP (male) and HepG2 (male) cell lines were grown in Dulbecco's Modified Eagle Medium (DMEM) GlutaMax (\#31966; Gibco, Invitrogen Life Technologies) supplemented with $10 \%$ fetal bovine serum (Pan biotech) and $1 \mathrm{X}$ PenicillinStreptomycin (Gibco). Caco-2 cells were supplemented with $1 X$ Non-essential amino acids mix (Gibco). GFP-MKLP1 cells were kept under G418 ( $40 \mu \mathrm{g} / \mathrm{mL}, \mathrm{GIBCO}$ ) selection and GFP-MKLP1 BST2 KO expressing one of the different BST2 constructs were kept under G418 and zeocin (50 $\mu \mathrm{g} / \mathrm{mL}$, Invitrogen) selection. Human TNF $\alpha$ (Thermofisher, \#PHC3015) was diluted at $20 \mu \mathrm{g} /$ $\mathrm{mL}$ in the cell culture medium for $30 \mathrm{~min}$. GFP-MKLP1 HeLa ITG $\alpha$ V KO cells were cultured on collagen-coated dishes (Corning, \#354236). All cell lines were grown in $5 \% \mathrm{CO}_{2} / 37^{\circ} \mathrm{C}$, and routinely tested for mycoplasma, maintained at sub-confluent densities and in low passage number. Primary HUVEC (female), primary T lymphocytes (gender not provided) and Caco-2 (male) were fixed and processed for immunofluorescence. 


\section{METHOD DETAILS}

\section{Plasmids, cloning and CRISPR/Cas9 KO clone testing}

The human BST2 coding sequence was cloned into a pcDNA3 plasmid. The kozak sequence of the plasmid was used to express BST2. BST2-GFP was generated as described in ref. ${ }^{54}$. Briefly, the GFP coding sequence was amplified with Pst1 restriction sites at $5^{\prime}$ and $3^{\prime}$ and ligated into the Pst1 site of BST2.

The plasmid pSpCas9(BB)-2A-Puro (PX459) V2.0 (Addgene) was a gift from Feng Zhang; http://n2t.net/addgene:62988 ; RRID:Addgene_6298866 in which we inserted the CTRL (5'AAGATGAAAGGAAAGGCGTT-3'), BST2 (5'- GCCGGACGGCCTTCGGGCA-3') or Integrin ITG $\alpha$ V (5'-CACCGGTGACTGGTCTTCTACCCGC - $3^{\prime}$ ) KO guide using the Bbsl restriction sites. The primer pair 5'- GCCCGTAGAAGATTCCAGCA-3' and 5'-GGAAGCCATTAGGGCCATCTAA-3' was used to amplify and clone BST2 from genomic DNA in TOPO vector (Invitrogen) for sequencing. 5'GCCCGTAGAAGATTCCAGCA -3' and 5'- TGTTCAAGCGAAAAGCCGAG-3' primers were used to amplify the RT product, which was migrated on agarose gel and extracted for sequencing.

BST2 lentiviral constructions for transduction: The lentiviral expression plasmids encoding for the different BST2 mutants were made as follows: all point mutations have been generated from the pcDNA3 BST2 plasmid using NEBaseChanger (NEB) and appropriate primers (See table S1), including BST2 C3A (C53A, C63A, C91A), BST2 Y2A (Y6A, Y8A), BST2 delGPI (S161STOP). BST2 mutants were amplified by PCR and introduced into pENTR gateway vectors, then recombined into the pLenti/V5 destination vector (ThermoFisher scientific). V5 tag is not expressed as the BST2 STOP codon was conserved.

\section{Stable cell lines}

BST2 KO cell line using CRISPR/Cas9 technology

CTRL KO and BST2 KO HeLa cells expressing GFP-MKLP1 and non-fluorescent HeLa Kyoto cells were created using the plasmid pSpCas9(BB)-2A-Puro with the appropriate guides as described above. Cells were selected with $1.5 \mu \mathrm{g} / \mathrm{mL}$ puromycin and clones were isolated and tested for KO using genomic PCR and RT-PCR, followed by sequencing.

\section{ITG $\alpha$ V KO cell lines using CRISPR/Cas9 technology}

Either CTRL KO or BST2 KO HeLa cells expressing GFP-MKLP1 (see above) were edited using the plasmid pSpCas9(BB)-2A-Puro with either CTRL or ITG $\alpha$ V guides. Cells were selected with $1.5 \mu \mathrm{g} / \mathrm{mL}$ puromycin for 4 days, and sorted by FACS after surface immunostaining with a rabbit anti-ITG $\alpha$ V antibody (1:100; Proteintech Group 27096-1-AP) coupled with a fluorescent secondary antibody.

\section{BST2 mutant cell lines using lentiviral transduction}

Lentiviral particles were produced in the HEK293 FT packaging cells using standard methods. Briefly, cells were co-transfected with the different pLenti-BST2 constructs and the Excelenti LTX Lentivirus Packaging mix (Oxford Genetics) using lipofectamine as per manufacturer's 
protocol. After $48 \mathrm{~h}$, the HEK293 FT culture supernatants were added to BST2 KO GFP-MKLP1 HeLa cells for $24 \mathrm{~h}$. Cells were selected for stable expression with $100 \mu \mathrm{g} / \mathrm{mL}$ zeocin and BST2positive cells were then sorted by FACS after immunostaining with the APC-coupled anti-BST2 antibody (\#BLE388410, OZYME).

\section{Flow cytometry samples}

\section{MBR purification}

MBRs were purified as previously described for GFP-MKLP2 HeLa cells in ref. ${ }^{35}$. Briefly, MBRs were detached from HeLa GFP-MKLP1 cells with a 2 mM EDTA-treatment. The supernatant from the $70 \mathrm{~g}$ centrifugation was collected and sorting of MBRs was performed on a BD Biosciences FACS ARIA III. The Threshold based on FSC was set at 250, and Neutral Density filter 1.0 has been used to detect small particles. MBRs were gated on a pseudo-color plot looking at GFP versus SSC-A parameters, both in log scales (Figure S1B).

\section{BST2 level measurements}

GFP-MKLP1 HeLa cells grown to sub-confluency were stained on ice with an APC-coupled isotype control (1:200; BioLegend \#BLE400121) or the anti-BST2 (1:100; BioLegend\#BLE348410) antibody for $20 \mathrm{~min}$. Then cells and MBRs were detached with $2 \mathrm{mM}$ EDTA-treatment and the sample was processed on a BD Biosciences FACS ARIA III. Cells were acquired using Neutral Density filter 2.0 and the MBRs acquired using Neutral Density filter 1.0 .

\section{Quantification of MBRs in culture media}

Culture media from CTRL KO and BST2 KO GFP-MKLP1 cells grown for three days were harvested and a fraction of the sample was mixed with a known quantity of fluorescent beads (123count ebeads, Invitrogen \#15526296). We acquired simultaneously fluorescent beads, calibrated at a known concentration, and MBRs from the same sample media and then extrapolated the total number of MBRs in the whole culture medium. Each condition was normalized to the number of cells.

\section{Cell cycle experiment and Ki67 labelling}

Non-confluent GFP-MKLP1 HeLa cells were EDTA-detached, washed twice with ice-cold PBS and fixed $30 \mathrm{~min}$ with ice-cold $80 \%$ Ethanol. $10^{6}$ cells were washed with PBS and permeabilized in $0,2 \%$ Triton. Fixed cells were then washed and saturated for $20 \mathrm{~min}$ with $1 \%$ FCS. Cells were incubated with $1 \mu \mathrm{g} / \mathrm{mL}$ DAPI (Serva) and anti-Ki67 coupled with APC (or matched APC isotype) in $1 \%$ FCS/PBS for $30 \mathrm{~min}$. Cell cycle and Ki67 fluorescence were acquired with the CytExpert 2.4.0.028 on a CytoFLEX S (Beckman Coulter, France). DAPI signal was measured using a 405-450/45nm filter. FSC/SSC parameters were used for cell size and doublets excluded from the analysis. 10,000 singlets were recorded for each condition and analyzed with FlowJo. 


\section{Spinoculation of MBRs}

On glass coverslips

Purified GFP+ MBRs isolated by flow cytometry were spinoculated at $1200 \mathrm{~g}$ for 45 min onto a poly-lysine coated coverslip and then processed for immunofluorescence.

On cells

Purified GFP+ MBRs isolated by flow cytometry were spinoculated at $1200 \mathrm{~g}$ for 15 min onto cells in DMEM + Hepes $25 \mathrm{mM}$ (Gibco) at $30^{\circ} \mathrm{C}$. Then, the cells were incubated another $30 \mathrm{~min}$ in the incubator at $37{ }^{\circ} \mathrm{C} / 5 \% \mathrm{CO}_{2}$. The medium was washed with fresh medium to remove MBRs that did not attach properly, and cells were then acquired with time-lapse imaging.

\section{Co-culture experiments}

WT, non-fluorescent HeLa cells were incubated with either CTRL KO or BST2 KO GFP-MKLP1 HeLa cells, in a 1:1 ratio. Cells were grown for 48 hours, then fixed and processed for IF. The percentage of transferred MBRs (number of GFP-MKLP1 MBRs transferred onto nonfluorescent HeLa cells divided by the total number of GFP-MKLP1 MBRs) was quantified.

\section{Immunofluorescence and image acquisition}

Cells were grown on coverslips and then fixed with $4 \%$ paraformaldehyde (PFA) for 10 min at room temperature. Cells were permeabilized with $0.1 \%$ Triton-X100 for 3 min, blocked with $0.2 \% \mathrm{BSA} / \mathrm{PBS}$ for $20 \mathrm{~min}$ and successively incubated for $1 \mathrm{~h}$ at room temperature with primary and secondary antibodies diluted in PBS containing $0.2 \%$ BSA.

For surface staining, live cells were saturated with $0.2 \%$ BSA/PBS for 10 min on ice, then incubated with primary antibodies (anti-CD81 or anti-CD9P1) diluted in $0.2 \%$ BSA/PBS for 30 min on ice. Cells were fixed with $4 \%$ PFA for 10 min at room temperature, and either directly incubated with secondary antibodies diluted in PBS containing $0.2 \%$ BSA, or permeabilized with $0.1 \%$ Triton-X100 for $3 \mathrm{~min}$, saturated with $0.2 \%$ BSA/PBS for 5 min and successively incubated for $1 \mathrm{~h}$ at room temperature with primary (anti-GFP and/or antiLamp1) and secondary antibodies diluted in PBS with $0.2 \%$ BSA.

Cells were immunostained with the following primary antibodies: rabbit anti-BST2 (1:500; Proteintech Group \#13560-1-AP), mouse anti-Cep55 (1:500; Santa Cruz \#sc-374051), mouse anti-CRIK (1:500; BD Bioscience \# 611376), mouse anti-CD81 (described in ref. ${ }^{50}$ ) and mouse anti-CD9P1 (1:100; kindly provided by E. Rubinstein), rabbit anti-Lamp1 (1:500 ABCAM \#ab24170), chicken anti-GFP (1:1000, ABCAM \#ab13970), human anti-acetylated tubulin (1:500; Institut Curie \# A-R-H\#39). Secondary antibodies (1:500; Jackson ImmunoResearch) were diluted in PBS containing $0.2 \%$ BSA. Cells were mounted in Mowiol (Calbiochem) after DAPI staining $(0.5 \mu \mathrm{g} / \mathrm{mL}$, Serva). Images were acquired with an inverted TiE Nikon microscope, using a x100 1.4 NA PL-APO objective lens or a x60 1.4 NA PL-APO VC objective lens and MetaMorph software (MDS) driving a CCD camera (Photometrics Coolsnap HQ). Images were then converted into 8-bit images using ImageJ software (NIH). 


\section{Cell adhesion assay}

The experiment was performed as described in ref. ${ }^{14}$. Briefly, detached cells were incubated 30 min on ice with $40 \mu \mathrm{M}$ RADfV or RGDfV peptides, and then seeded on fibronectin-coated coverslips for $15 \mathrm{~min}$ to allow them to adhere. The cells were then fixed with 4\% PFA, permabilized with $0.1 \%$ Triton-X100 for 3 min, stained with DAPI and mounted in Mowiol.

\section{Time-lapse microscopy}

For the MBR release experiments, HeLa cells were plated on glass bottom 12-well plates (MatTek) or on collagen-coated 96-well plates for the ITG $\alpha$ V KO experiment (Greiner), and put in an open chamber (Life Imaging) equilibrated to $5 \% \mathrm{CO} 2$ and maintained at $37^{\circ} \mathrm{C}$.

For long term imaging (Figure 3A-C, 3G-H, 4D-F, S4C), time-lapse sequences were recorded every $15 \mathrm{~min}$ for $48 \mathrm{~h}$ using a NikonEclipse TiE inverted microscope with a x20 objective lens 0.45 NA Plan Fluor ELWD controlled by Metamorph software (Universal Imaging). The midbody of a mitotic cell was followed from its abscission until it was degraded, released or until the time-lapse ended. For BST2-GFP time-lapse fluorescent microscopy, images were acquired every $10 \mathrm{~min}$ for $16 \mathrm{~h}$ using an inverted Eclipse TiE Nikon microscope equipped with a CSU-X1 spinning disk confocal scanning unit (Yokogawa) and with an EMCCD Camera (Evolve 512 Delta, Photometrics). Images were acquired with a x60 1.4 NA PL-APO VC and MetaMorph software (MDS).

For RADfV/RGDFV treatments (Figure $4 \mathrm{~A}$ ), the medium was replaced with either DMEM, $\mathrm{DMEM}+40 \mu \mathrm{M}$ RADfV or DMEM + $40 \mu \mathrm{M}$ RGDfV, and time-lapse sequences were recorded every 15 min for $6 \mathrm{~h}$, using a NikonEclipse TiE inverted microscope with a x20 objective lens 0.45 NA Plan Fluor ELWD controlled by Metamorph software (Universal Imaging). MBRs present at t0 were followed until they were degraded, released or until the time-lapse ended.

For EDTA treatment (Figure 4B), the medium was replaced with either DMEM or DMEM + 4.6 mM EDTA and time-lapse sequences with z-stacks were recorded every 5 min for $3 \mathrm{~h}$, using an inverted Eclipse TiE Nikon microscope equipped with a CSU-X1 spinning disk confocal scanning unit (Yokogawa) and with an EMCCD Camera (Evolve 512 Delta, Photometrics). MBRs present at to were followed until they were degraded, released or until the time-lapse ended. MBs in intercellular bridges were excluded from the analysis using a tubulin staining, Sir-tubulin (Tebu-bio, \#SC002).

\section{SIM microscopy}

SIM was performed on a Zeiss LSM 780 Elyra PS1 microscope (Carl Zeiss, Germany) using C Plan-Apochromat $63 \times / 1.4$ oil objective with a 1.518 refractive index oil (Carl Zeiss). The fluorescence signal was detected on an EMCCD Andor Ixon 887 1K. Raw images were composed of fifteen images per plane per channel (five phases, three angles), and acquired with a Z-distance of $0.091 \mu \mathrm{m}$. SIM images were corrected for chromatic aberration using 100- 
$\mathrm{nm}$ TetraSpeck microspheres (ThermoFisher Scientific) embedded in the same mounting media as the sample. The SIMcheck plugin ${ }^{67}$ in ImageJ was used to analyze the quality of the acquisition and the processing in order to optimize parameters for resolution, signal-to-noise ratio, and reconstruction pattern.

\section{Western blots}

Western blots were carried out as follows: cells were lysed in NP-40 extract buffer $(50 \mathrm{mM}$ Tris, $\mathrm{pH} 8,150 \mathrm{mM} \mathrm{NaCl}, 1 \% \mathrm{NP}-40$ ) containing protease inhibitors. $20 \mu \mathrm{g}$ of lysate was migrated in 4-15\% gradient SDS-PAGE gels (BioRad Laboratories), transferred onto PVDF membranes (Millipore) and incubated with indicated primary antibodies in PBS, $1 \%$ low-fat milk and $0.1 \%$ Tween 20 . The membranes were incubated with HRP-coupled secondary antibodies (1:10,000, Jackson ImmunoResearch) and revealed by chemiluminescence (GE Healthcare). For western blots against deglycosylated BST2, the cell extracts were deglycosylated with PNGase F (New England Biolabs, \#P0704S) for $3 \mathrm{~h}$ at room temperature before processing with the SDS-PAGE.

\section{QUANTIFICATION AND STATISTICAL ANALYSIS}

All values are displayed as mean \pm SD (standard deviation) for at least three independent experiments (as indicated in the figure legends). Significance was calculated using paired, twosided $t$-tests or ANOVA tests, as indicated. In all statistical tests $p>0.05$ was considered as non-significant. $p$ values are indicated in each individual graph.

\section{SUPPLEMENTAL VIDEO TITLES AND LEGENDS}

Video S1: GFP-BST2 localization throughout cell division. Related to Figure 1.

Time-lapse fluorescent microscopy of GFP-BST2 expressing HeLa cells throughout mitosis and cytokinesis. SiR-Tubulin labels the intercellular bridge and the MBR. Merge (left) and BST2 (right) channels are displayed. Time 0 corresponds to furrow ingression. 


\section{REFERENCES}

1. Mierzwa, B., and Gerlich, D.W. (2014). Cytokinetic Abscission: Molecular Mechanisms and Temporal Control. Developmental cell 31, 525-538.

2. D'Avino, P.P., and Capalbo, L. (2016). Regulation of midbody formation and function by mitotic kinases. Seminars in cell \& developmental biology 53, 57-63.

3. Stoten, C.L., and Carlton, J.G. (2017). ESCRT-dependent control of membrane remodelling during cell division. Seminars in cell \& developmental biology.

4. Addi, C., Bai, J., and Echard, A. (2018). Actin, microtubule, septin and ESCRT filament remodeling during late steps of cytokinesis. Current opinion in cell biology 50, 27-34.

5. Fremont, S., and Echard, A. (2018). Membrane Traffic in the Late Steps of Cytokinesis. Current biology : CB 28, R458-R470.

6. Dubreuil, V., Marzesco, A.M., Corbeil, D., Huttner, W.B., and Wilsch-Brauninger, M. (2007). Midbody and primary cilium of neural progenitors release extracellular membrane particles enriched in the stem cell marker prominin-1. The Journal of cell biology 176, 483-495.

7. Kuo, T.C., Chen, C.T., Baron, D., Onder, T.T., Loewer, S., Almeida, S., Weismann, C.M., Xu, P., Houghton, J.M., Gao, F.B., et al. (2011). Midbody accumulation through evasion of autophagy contributes to cellular reprogramming and tumorigenicity. Nature cell biology 13, 1214-1223.

8. Chen, C.T., Ettinger, A.W., Huttner, W.B., and Doxsey, S.J. (2013). Resurrecting remnants: the lives of post-mitotic midbodies. Trends in cell biology 23, 118-128.

9. Crowell, E.F., Tinevez, J.Y., and Echard, A. (2013). A simple model for the fate of the cytokinesis midbody remnant: implications for remnant degradation by autophagy: modeling remnant production and degradation enables re-interpretation of published data and improves design of future experiments. Bioessays 35, 472-481.

10. Crowell, E.F., Gaffuri, A.L., Gayraud-Morel, B., Tajbakhsh, S., and Echard, A. (2014). Midbody remnant engulfment after cytokinesis abscission in mammalian cells. J Cell Sci $127,3840-3851$.

11. Dionne, L.K., Wang, X.J., and Prekeris, R. (2015). Midbody: from cellular junk to regulator of cell polarity and cell fate. Current opinion in cell biology 35, 51-58.

12. McNeely, K.C., and Dwyer, N.D. (2020). Cytokinesis and postabscission midbody remnants are regulated during mammalian brain development. Proceedings of the National Academy of Sciences of the United States of America 117, 9584-9593.

13. Lujan, P., Varsano, G., Rubio, T., Hennrich, M.L., Sachsenheimer, T., GalvezSantisteban, M., Martin-Belmonte, F., Gavin, A.C., Brugger, B., and Kohn, M. (2016). PRL-3 disrupts epithelial architecture by altering the post-mitotic midbody position. $\mathrm{J}$ Cell Sci 129, 4130-4142.

14. Peterman, E., Gibieza, P., Schafer, J., Skeberdis, V.A., Kaupinis, A., Valius, M., Heiligenstein, X., Hurbain, I., Raposo, G., and Prekeris, R. (2019). The post-abscission midbody is an intracellular signaling organelle that regulates cell proliferation. Nat Commun 10, 3181.

15. Singh, D., and Pohl, C. (2014). Coupling of Rotational Cortical Flow, Asymmetric Midbody Positioning, and Spindle Rotation Mediates Dorsoventral Axis Formation in C. elegans. Developmental cell 28, 253-267.

16. Peterman, E., and Prekeris, R. (2019). The postmitotic midbody: Regulating polarity, stemness, and proliferation. The Journal of cell biology 218, 3903-3911.

17. Neil, S.J., Zang, T., and Bieniasz, P.D. (2008). Tetherin inhibits retrovirus release and is antagonized by HIV-1 Vpu. Nature 451, 425-430. 
18. Van Damme, N., Goff, D., Katsura, C., Jorgenson, R.L., Mitchell, R., Johnson, M.C., Stephens, E.B., and Guatelli, J. (2008). The interferon-induced protein BST-2 restricts HIV-1 release and is downregulated from the cell surface by the viral Vpu protein. Cell host \& microbe 3, 245-252.

19. Neil, S.J. (2013). The antiviral activities of tetherin. Curr Top Microbiol Immunol 371, 67-104.

20. Sauter, D. (2014). Counteraction of the multifunctional restriction factor tetherin. Front Microbiol 5, 163.

21. Carlton, J.G., and Martin-Serrano, J. (2007). Parallels between cytokinesis and retroviral budding: a role for the ESCRT machinery. Science 316, 1908-1912.

22. Morita, E., Sandrin, V., Chung, H.Y., Morham, S.G., Gygi, S.P., Rodesch, C.K., and Sundquist, W.I. (2007). Human ESCRT and ALIX proteins interact with proteins of the midbody and function in cytokinesis. The EMBO journal 26, 4215-4227.

23. Carlton, J.G., Agromayor, M., and Martin-Serrano, J. (2008). Differential requirements for Alix and ESCRT-III in cytokinesis and HIV-1 release. Proceedings of the National Academy of Sciences of the United States of America 105, 10541-10546.

24. Hurley, J.H. (2015). ESCRTs are everywhere. The EMBO journal 34, 2398-2407.

25. Scourfield, E.J., and Martin-Serrano, J. (2017). Growing functions of the ESCRT machinery in cell biology and viral replication. Biochemical Society transactions 45, 613-634.

26. Vietri, M., Radulovic, M., and Stenmark, H. (2020). The many functions of ESCRTs. Nature reviews. Molecular cell biology 21, 25-42.

27. Pohl, C., and Jentsch, S. (2009). Midbody ring disposal by autophagy is a postabscission event of cytokinesis. Nature cell biology 11, 65-70.

28. Elia, N., Sougrat, R., Spurlin, T.A., Hurley, J.H., and Lippincott-Schwartz, J. (2011). Dynamics of endosomal sorting complex required for transport (ESCRT) machinery during cytokinesis and its role in abscission. Proceedings of the National Academy of Sciences of the United States of America 108, 4846-4851.

29. Chai, Y., Tian, D., Yang, Y., Feng, G., Cheng, Z., Li, W., and Ou, G. (2012). Apoptotic regulators promote cytokinetic midbody degradation in $\mathrm{C}$. elegans. The Journal of cell biology 199, 1047-1055.

30. Lafaurie-Janvore, J., Maiuri, P., Wang, I., Pinot, M., Manneville, J.B., Betz, T., Balland, M., and Piel, M. (2013). ESCRT-III assembly and cytokinetic abscission are induced by tension release in the intercellular bridge. Science 339, 1625-1629.

31. Salzmann, V., Chen, C., Chiang, C.Y., Tiyaboonchai, A., Mayer, M., and Yamashita, Y.M. (2014). Centrosome-dependent asymmetric inheritance of the midbody ring in Drosophila germline stem cell division. Molecular biology of the cell 25, 267-275.

32. Bernabe-Rubio, M., Andres, G., Casares-Arias, J., Fernandez-Barrera, J., Rangel, L., Reglero-Real, N., Gershlick, D.C., Fernandez, J.J., Millan, J., Correas, I., et al. (2016). Novel role for the midbody in primary ciliogenesis by polarized epithelial cells. The Journal of cell biology 214, 259-273.

33. Fazeli, G., Trinkwalder, M., Irmisch, L., and Wehman, A.M. (2016). C. elegans midbodies are released, phagocytosed and undergo LC3-dependent degradation independent of macroautophagy. J Cell Sci 129, 3721-3731.

34. Ettinger, A.W., Wilsch-Brauninger, M., Marzesco, A.M., Bickle, M., Lohmann, A., Maliga, Z., Karbanova, J., Corbeil, D., Hyman, A.A., and Huttner, W.B. (2011). Proliferating versus differentiating stem and cancer cells exhibit distinct midbodyrelease behaviour. Nat Commun 2, 503.

35. Addi, C., Presle, A., Fremont, S., Cuvelier, F., Rocancourt, M., Milin, F., Schmutz, S., Chamot-Rooke, J., Douche, T., Duchateau, M., et al. (2020). The Flemmingsome 
reveals an ESCRT-to-membrane coupling via ALIX/syntenin/syndecan-4 required for completion of cytokinesis. Nat Commun 11, 1941.

36. Ishikawa, J., Kaisho, T., Tomizawa, H., Lee, B.O., Kobune, Y., Inazawa, J., Oritani, K., Itoh, M., Ochi, T., Ishihara, K., et al. (1995). Molecular cloning and chromosomal mapping of a bone marrow stromal cell surface gene, BST2, that may be involved in pre-B-cell growth. Genomics 26, 527-534.

37. Perez-Caballero, D., Zang, T., Ebrahimi, A., McNatt, M.W., Gregory, D.A., Johnson, M.C., and Bieniasz, P.D. (2009). Tetherin inhibits HIV-1 release by directly tethering virions to cells. Cell 139, 499-511.

38. Hinz, A., Miguet, N., Natrajan, G., Usami, Y., Yamanaka, H., Renesto, P., Hartlieb, B., McCarthy, A.A., Simorre, J.P., Gottlinger, H., et al. (2010). Structural basis of HIV-1 tethering to membranes by the BST-2/tetherin ectodomain. Cell host \& microbe 7, 314323.

39. Swiecki, M., Scheaffer, S.M., Allaire, M., Fremont, D.H., Colonna, M., and Brett, T.J. (2011). Structural and biophysical analysis of BST-2/tetherin ectodomains reveals an evolutionary conserved design to inhibit virus release. The Journal of biological chemistry 286, 2987-2997.

40. Hammonds, J., Wang, J.J., Yi, H., and Spearman, P. (2010). Immunoelectron microscopic evidence for Tetherin/BST2 as the physical bridge between HIV-1 virions and the plasma membrane. PLoS Pathog 6, e1000749.

41. Venkatesh, S., and Bieniasz, P.D. (2013). Mechanism of HIV-1 virion entrapment by tetherin. PLoS Pathog 9, e1003483.

42. Liberatore, R.A., and Bieniasz, P.D. (2011). Tetherin is a key effector of the antiretroviral activity of type I interferon in vitro and in vivo. Proceedings of the National Academy of Sciences of the United States of America 108, 18097-18101.

43. Strauss, J.D., Hammonds, J.E., Yi, H., Ding, L., Spearman, P., and Wright, E.R. (2016). Three-Dimensional Structural Characterization of HIV-1 Tethered to Human Cells. J Virol 90, 1507-1521.

44. Edgar, J.R., Manna, P.T., Nishimura, S., Banting, G., and Robinson, M.S. (2016). Tetherin is an exosomal tether. eLife 5.

45. Maliga, Z., Junqueira, M., Toyoda, Y., Ettinger, A., Mora-Bermudez, F., Klemm, R.W., Vasilj, A., Guhr, E., Ibarlucea-Benitez, I., Poser, I., et al. (2013). A genomic toolkit to investigate kinesin and myosin motor function in cells. Nature cell biology 15, 325-334.

46. Blasius, A.L., Giurisato, E., Cella, M., Schreiber, R.D., Shaw, A.S., and Colonna, M. (2006). Bone marrow stromal cell antigen 2 is a specific marker of type I IFN-producing cells in the naive mouse, but a promiscuous cell surface antigen following IFN stimulation. J Immunol 177, 3260-3265.

47. Erikson, E., Adam, T., Schmidt, S., Lehmann-Koch, J., Over, B., Goffinet, C., Harter, C., Bekeredjian-Ding, I., Sertel, S., Lasitschka, F., et al. (2011). In vivo expression profile of the antiviral restriction factor and tumor-targeting antigen CD317/BST2/HM1.24/tetherin in humans. Proceedings of the National Academy of Sciences of the United States of America 108, 13688-13693.

48. Blanco-Melo, D., Venkatesh, S., and Bieniasz, P.D. (2016). Origins and Evolution of tetherin, an Orphan Antiviral Gene. Cell host \& microbe 20, 189-201.

49. Charrin, S., Le Naour, F., Oualid, M., Billard, M., Faure, G., Hanash, S.M., Boucheix, C., and Rubinstein, E. (2001). The major CD9 and CD81 molecular partner. Identification and characterization of the complexes. The Journal of biological chemistry $276,14329-14337$. 
50. Charrin, S., Le Naour, F., Labas, V., Billard, M., Le Caer, J.P., Emile, J.F., Petit, M.A., Boucheix, C., and Rubinstein, E. (2003). EWI-2 is a new component of the tetraspanin web in hepatocytes and lymphoid cells. Biochem J 373, 409-421.

51. Goffinet, C., Homann, S., Ambiel, I., Tibroni, N., Rupp, D., Keppler, O.T., and Fackler, O.T. (2010). Antagonism of CD317 restriction of human immunodeficiency virus type 1 (HIV-1) particle release and depletion of CD317 are separable activities of HIV-1 Vpu. J Virol 84, 4089-4094.

52. Rollason, R., Dunstan, K., Billcliff, P.G., Bishop, P., Gleeson, P., Wise, H., Digard, P., and Banting, G. (2013). Expression of HIV-1 Vpu leads to loss of the viral restriction factor CD317/Tetherin from lipid rafts and its enhanced lysosomal degradation. PloS one 8 , e 75680 .

53. Madjo, U., Leymarie, O., Fremont, S., Kuster, A., Nehlich, M., Gallois-Montbrun, S., Janvier, K., and Berlioz-Torrent, C. (2016). LC3C Contributes to Vpu-Mediated Antagonism of BST2/Tetherin Restriction on HIV-1 Release through a Non-canonical Autophagy Pathway. Cell reports 17, 2221-2233.

54. Kupzig, S., Korolchuk, V., Rollason, R., Sugden, A., Wilde, A., and Banting, G. (2003). Bst-2/HM1.24 is a raft-associated apical membrane protein with an unusual topology. Traffic 4, 694-709.

55. Tokarev, A., Suarez, M., Kwan, W., Fitzpatrick, K., Singh, R., and Guatelli, J. (2013). Stimulation of NF-kappaB activity by the HIV restriction factor BST2. J Virol 87, 20462057.

56. Eskens, F.A., Dumez, H., Hoekstra, R., Perschl, A., Brindley, C., Bottcher, S., Wynendaele, W., Drevs, J., Verweij, J., and van Oosterom, A.T. (2003). Phase I and pharmacokinetic study of continuous twice weekly intravenous administration of Cilengitide (EMD 121974), a novel inhibitor of the integrins alphavbeta3 and alphavbeta5 in patients with advanced solid tumours. Eur J Cancer 39, 917-926.

57. Kooyman, D.L., Byrne, G.W., McClellan, S., Nielsen, D., Tone, M., Waldmann, H., Coffman, T.M., McCurry, K.R., Platt, J.L., and Logan, J.S. (1995). In vivo transfer of GPI-linked complement restriction factors from erythrocytes to the endothelium. Science 269, 89-92.

58. Muller, G.A. (2018). The release of glycosylphosphatidylinositol-anchored proteins from the cell surface. Arch Biochem Biophys 656, 1-18.

59. Billcliff, P.G., Rollason, R., Prior, I., Owen, D.M., Gaus, K., and Banting, G. (2013). CD317/tetherin is an organiser of membrane microdomains. J Cell Sci 126, 1553-1564.

60. Lehmann, M., Rocha, S., Mangeat, B., Blanchet, F., Uji, I.H., Hofkens, J., and Piguet, V. (2011). Quantitative multicolor super-resolution microscopy reveals tetherin HIV-1 interaction. PLoS Pathog 7, e1002456.

61. Atilla-Gokcumen, G.E., Muro, E., Relat-Goberna, J., Sasse, S., Bedigian, A., Coughlin, M.L., Garcia-Manyes, S., and Eggert, U.S. (2014). Dividing cells regulate their lipid composition and localization. Cell 156, 428-439.

62. Mahauad-Fernandez, W.D., DeMali, K.A., Olivier, A.K., and Okeoma, C.M. (2014). Bone marrow stromal antigen 2 expressed in cancer cells promotes mammary tumor growth and metastasis. Breast Cancer Res 16, 493.

63. Zhang, G., Li, X., Chen, Q., Li, J., Ruan, Q., Chen, Y.H., Yang, X., and Wan, X. (2019). CD317 Activates EGFR by Regulating Its Association with Lipid Rafts. Cancer Res 79, 2220-2231.

64. Doyon, J.B., Zeitler, B., Cheng, J., Cheng, A.T., Cherone, J.M., Santiago, Y., Lee, A.H., Vo, T.D., Doyon, Y., Miller, J.C., et al. (2011). Rapid and efficient clathrin-mediated endocytosis revealed in genome-edited mammalian cells. Nature cell biology 13, 331337. 
65. Pineau, P., Marchio, A., Mattei, M.G., Kim, W.H., Youn, J.K., Tiollais, P., and Dejean, A. (1998). Extensive analysis of duplicated-inverted hepatitis B virus integrations in human hepatocellular carcinoma. J Gen Virol 79 ( Pt 3), 591-600.

66. Ran, F.A., Hsu, P.D., Wright, J., Agarwala, V., Scott, D.A., and Zhang, F. (2013). Genome engineering using the CRISPR-Cas9 system. Nature protocols 8, 2281-2308.

67. Ball, G., Demmerle, J., Kaufmann, R., Davis, I., Dobbie, I.M., and Schermelleh, L. (2015). SIMcheck: a Toolbox for Successful Super-resolution Structured Illumination Microscopy. Scientific reports 5, 15915. 

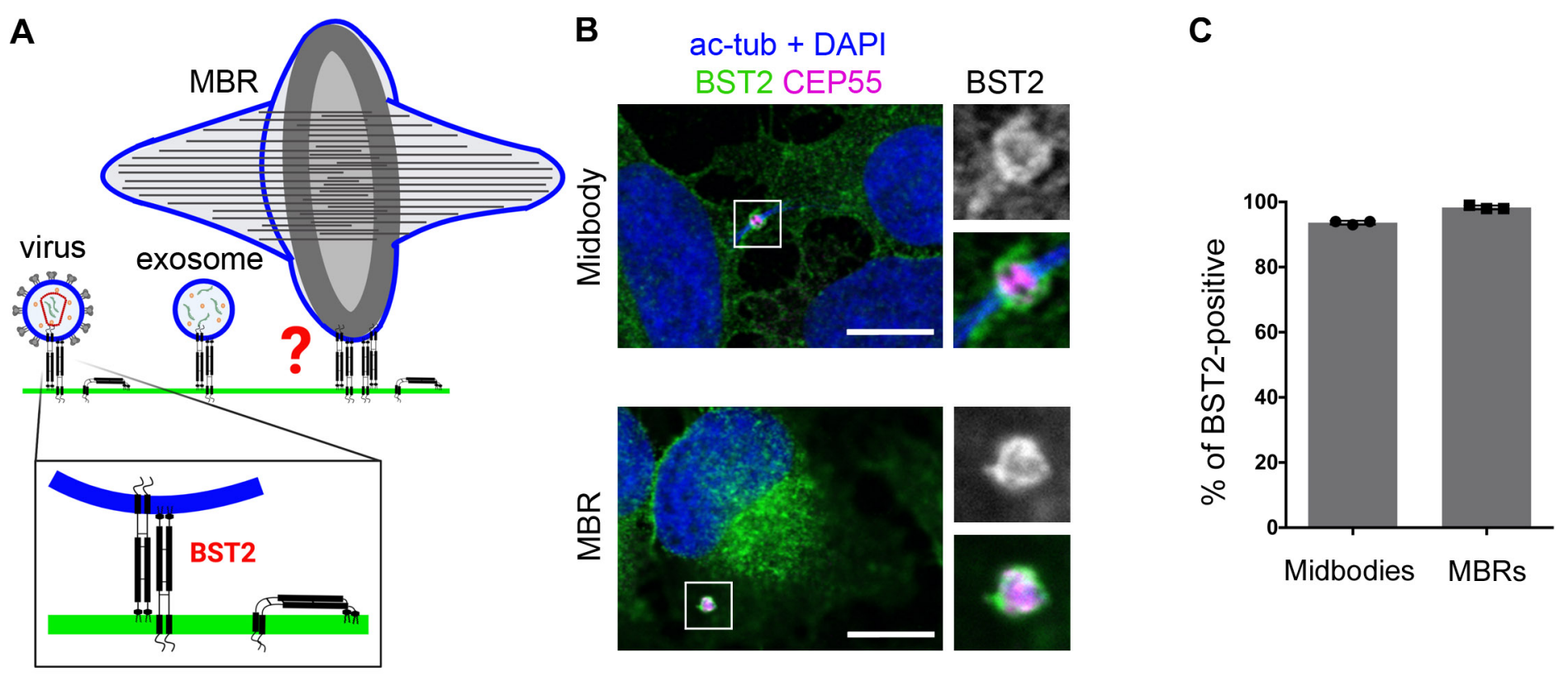

D
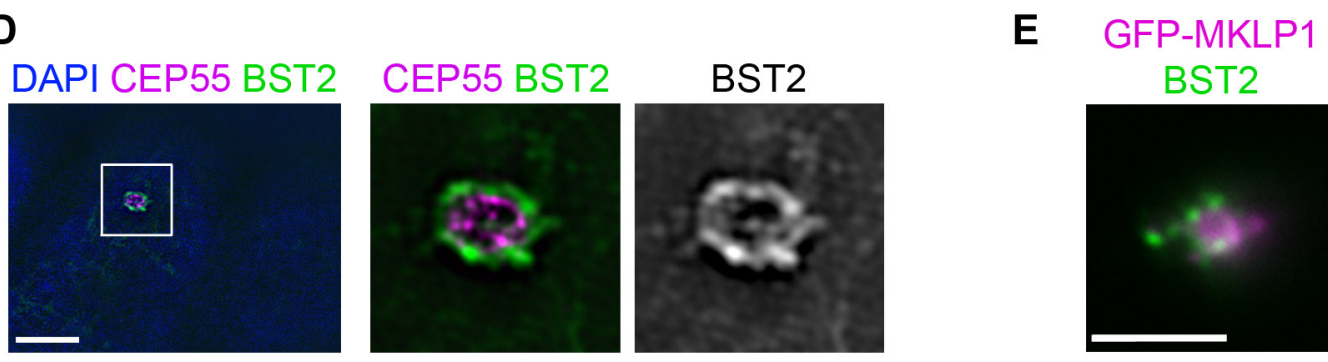

\section{F SiR-Tubulin BST2-GFP}
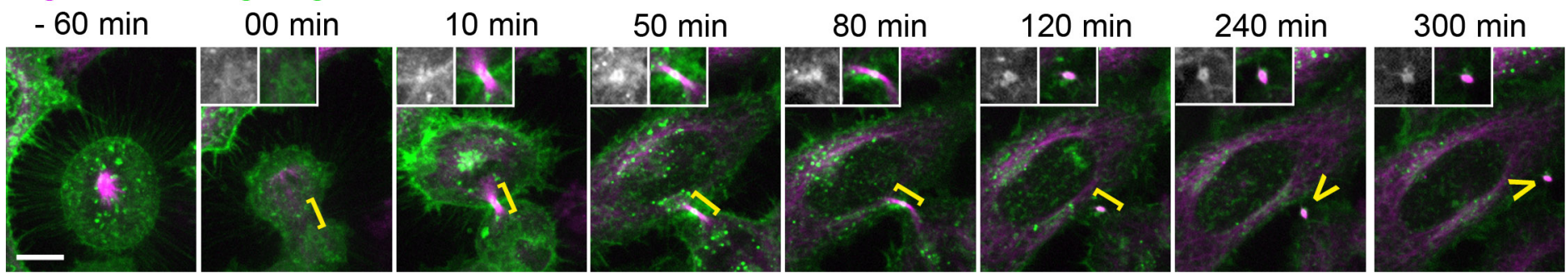

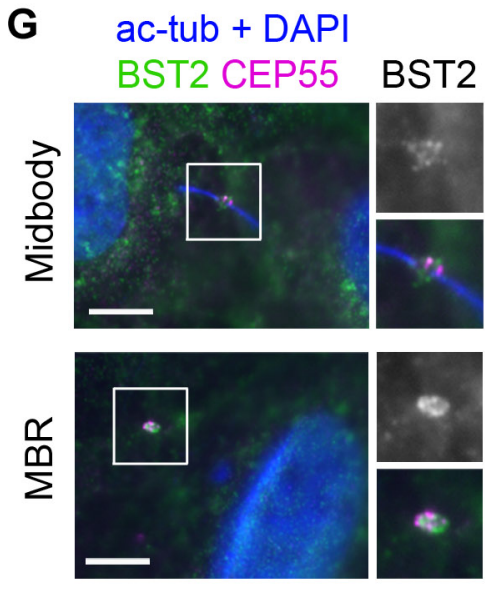

Caco-2

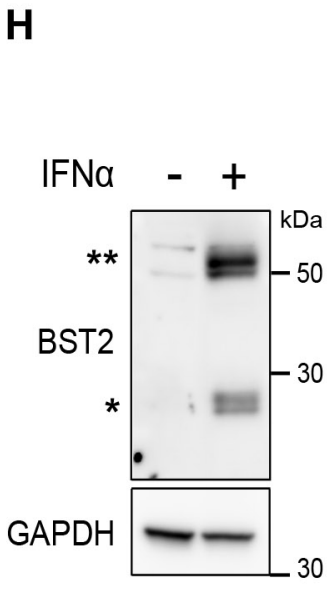

HEK 293

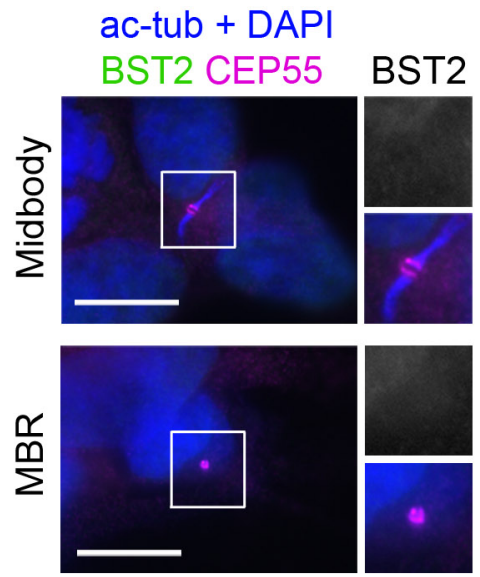

- IFNa

HEK 293

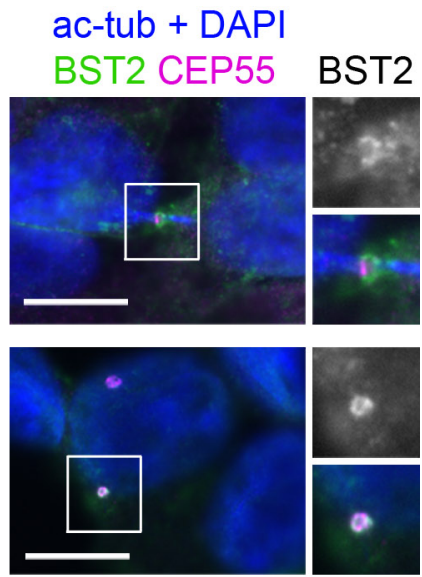

$+\mathrm{IFNa}$ HEK 293 
A

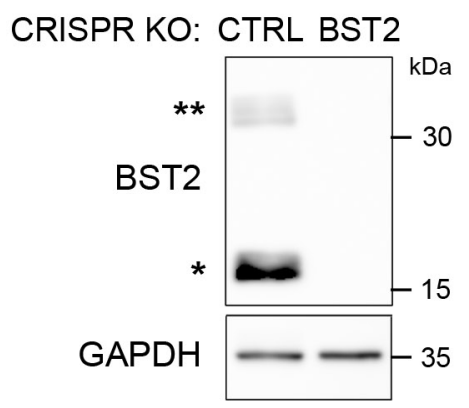

HeLa GFP-MKLP1
B

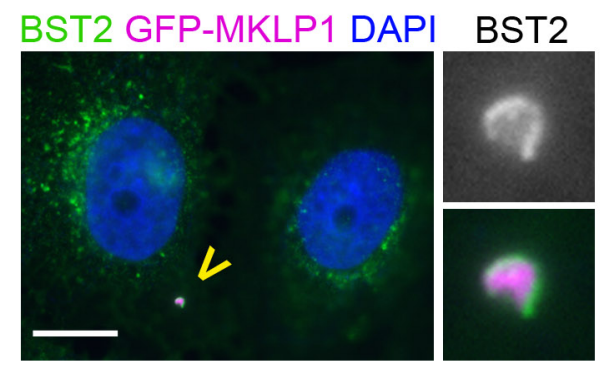

CTRL KO

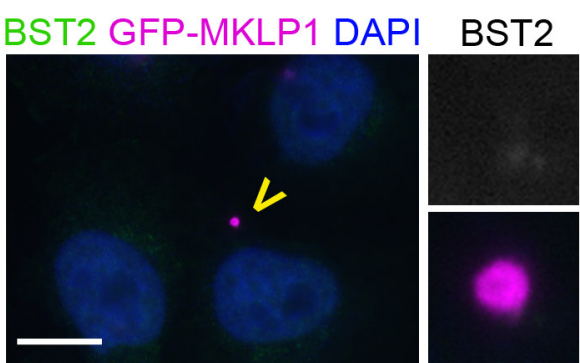

BST2 KO

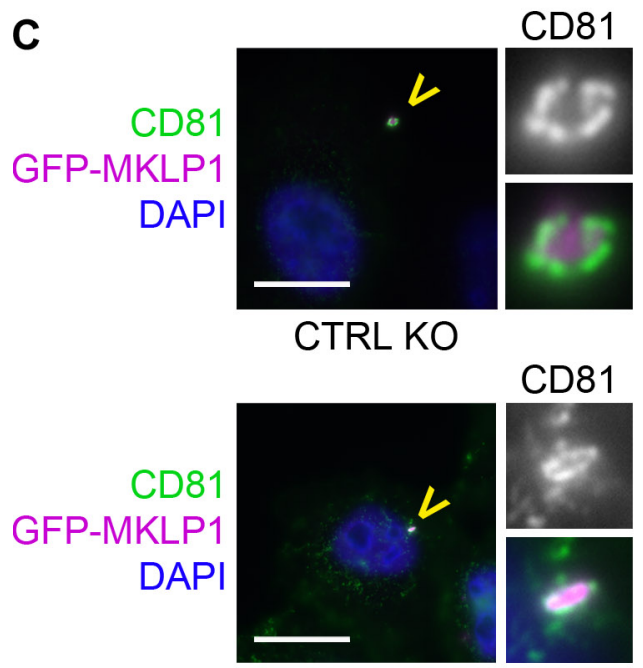

BST2 KO

E

\section{co-culture}

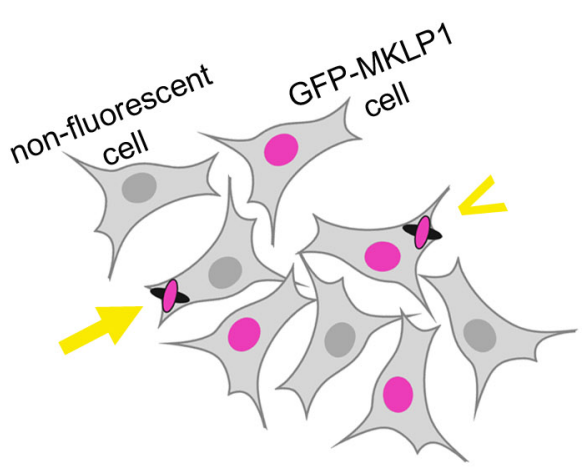

Merge
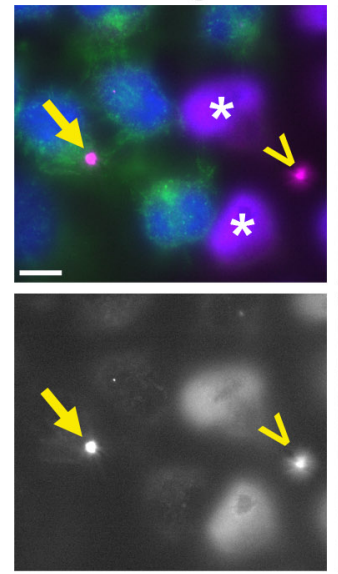

GFP-MKLP1

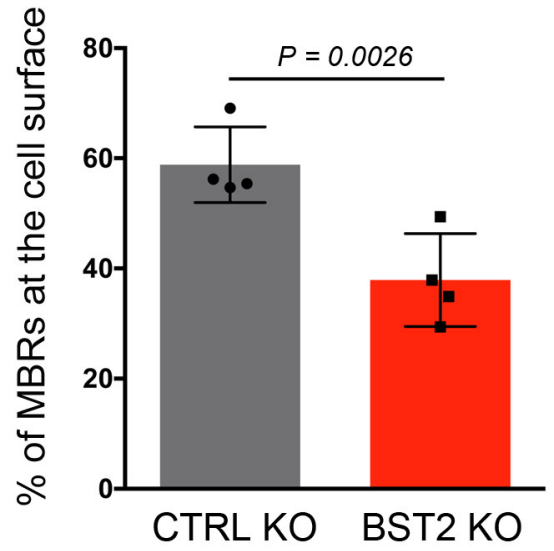

DAPI
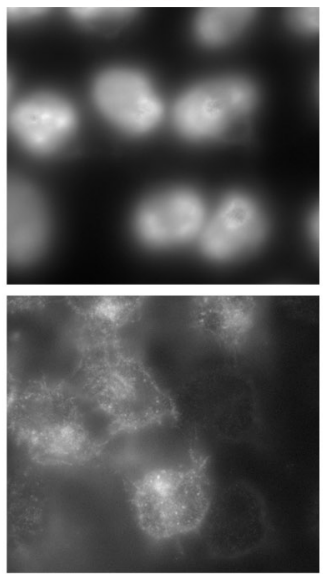

BST2
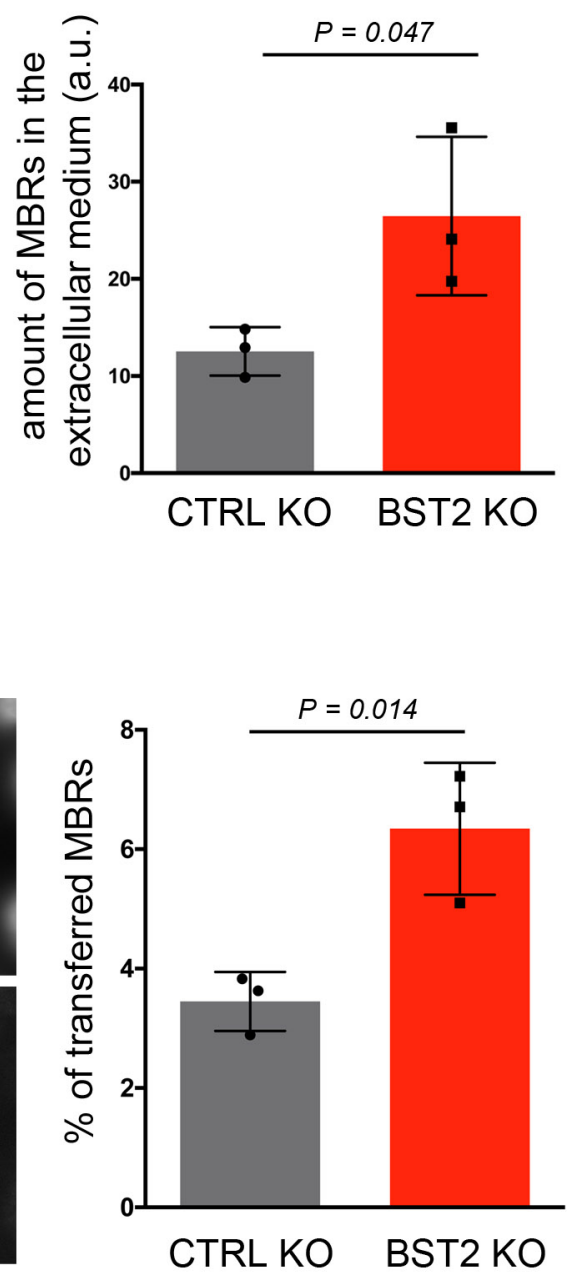
A Trans Light GFP-MKLP1

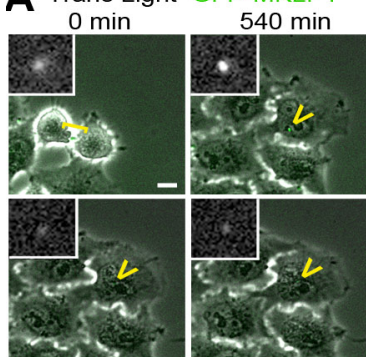

$630 \mathrm{~min}$

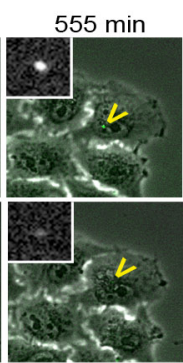

$660 \mathrm{~min}$

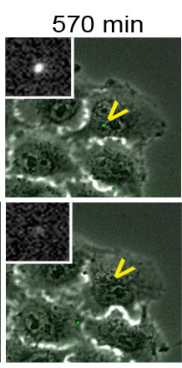

$675 \mathrm{~min}$

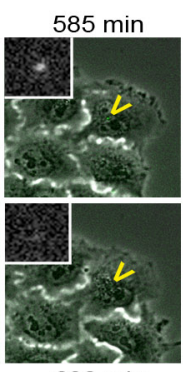

$690 \mathrm{~min}$

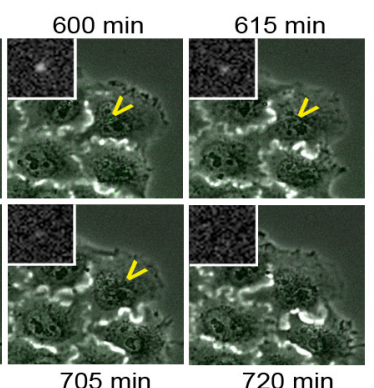

720 min

C

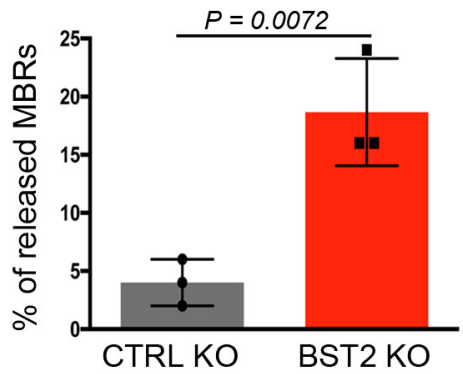

B Trans Light GFP-MKLP1

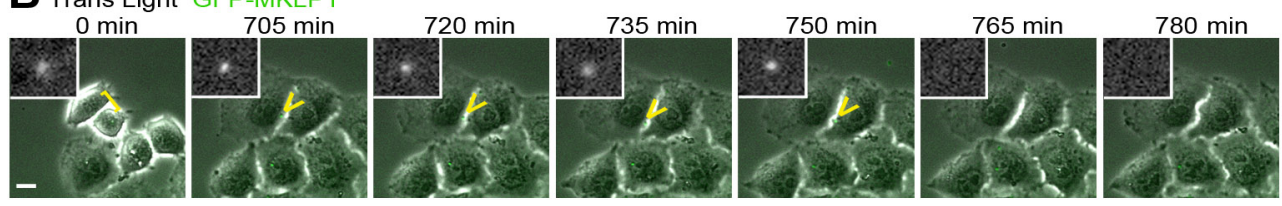

\section{E}

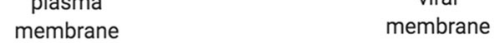

D
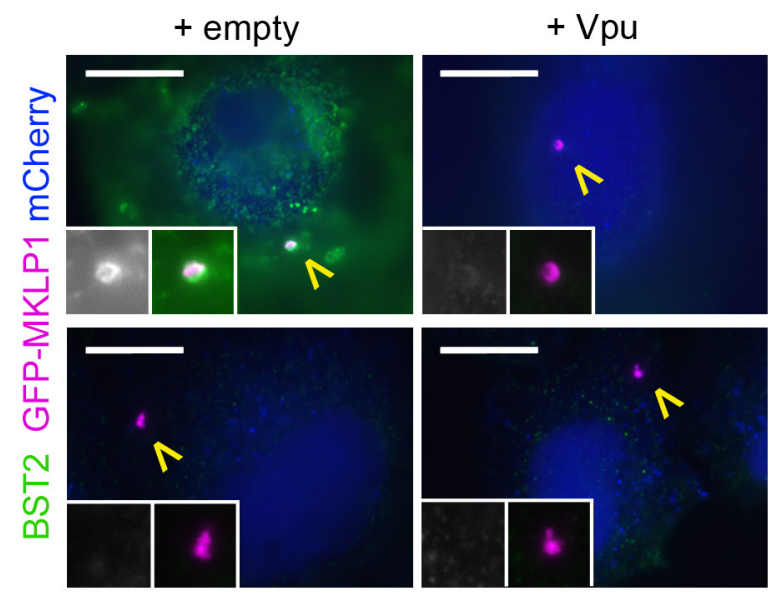

CTRL KO

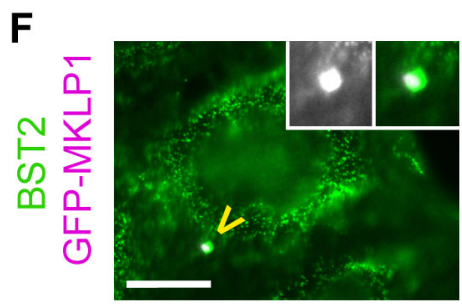

CTRL KO

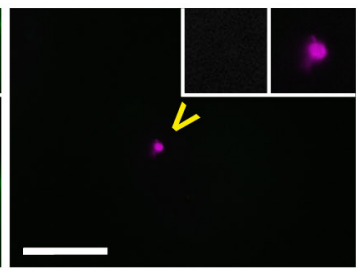

BST2 KO

BST2 KO
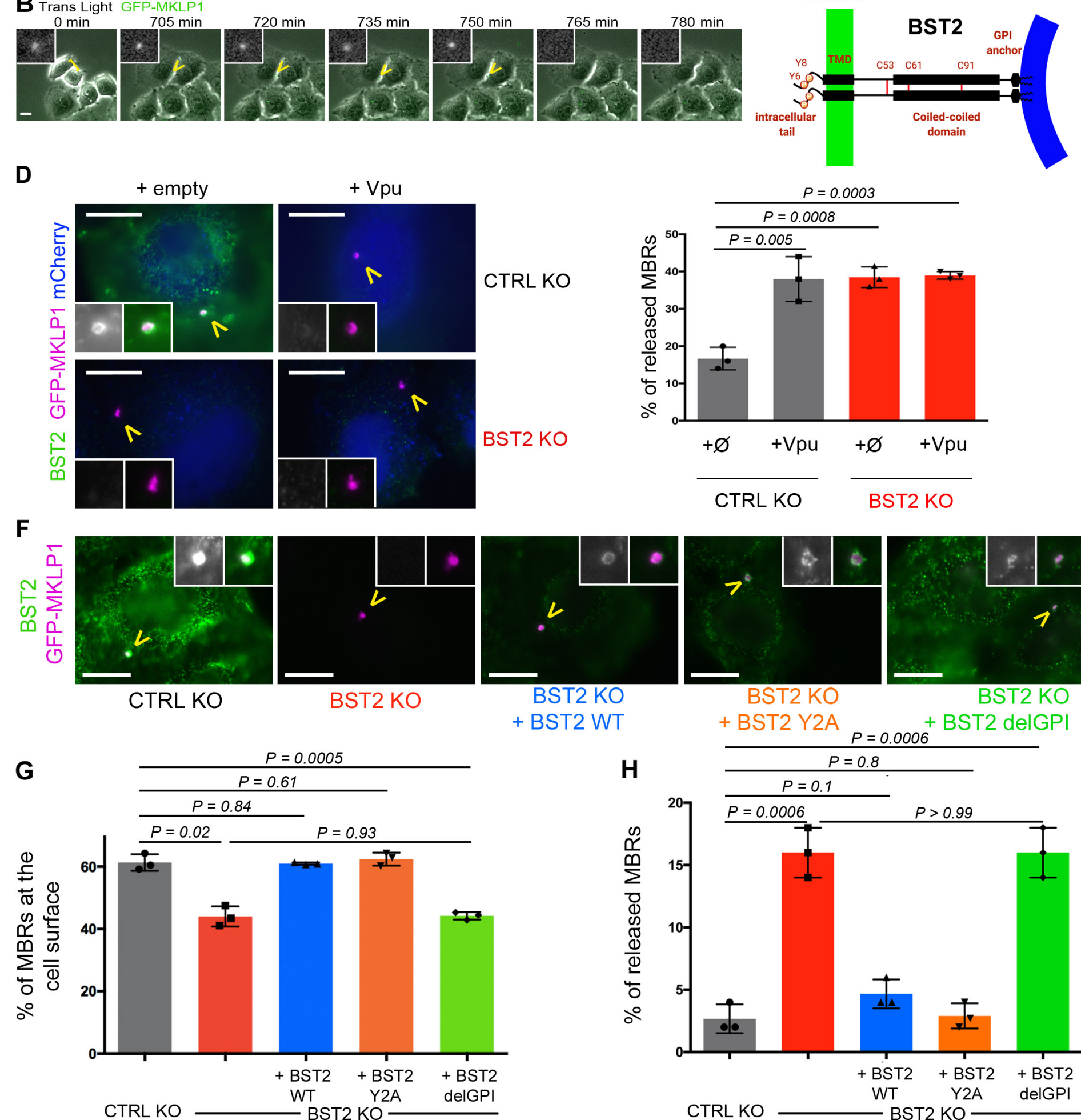

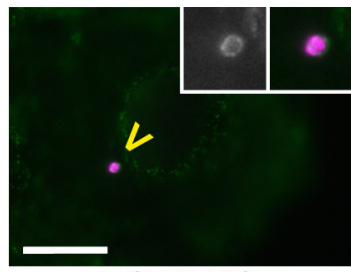

BST2 KO

+ BST2 WT

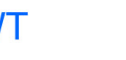

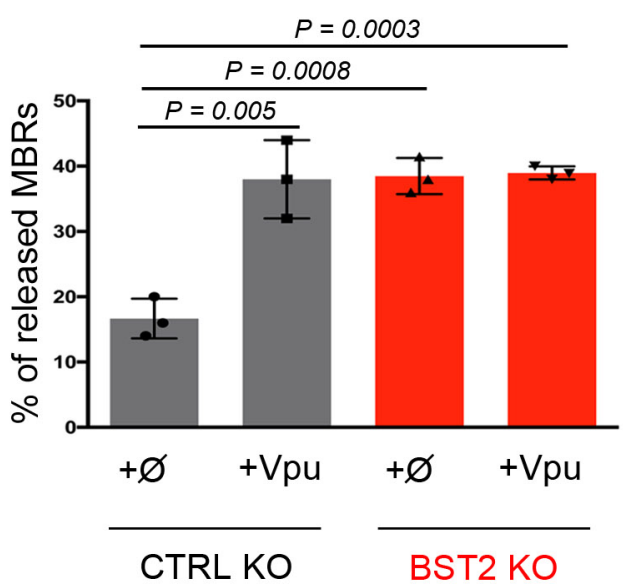
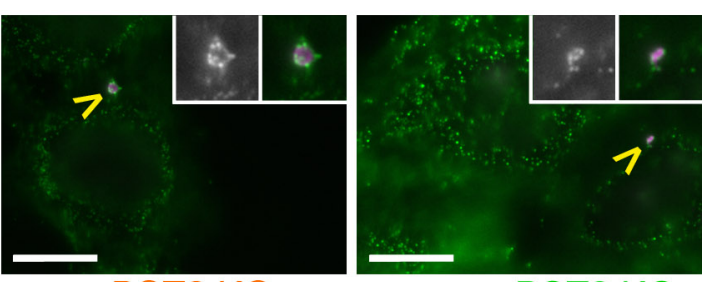

BST2 KO

+ BST2 delGPI

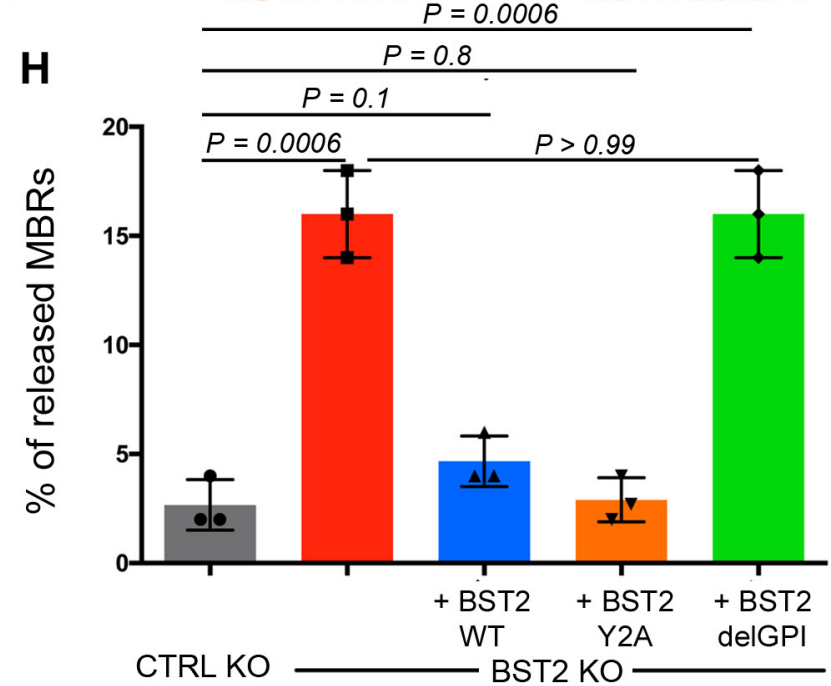



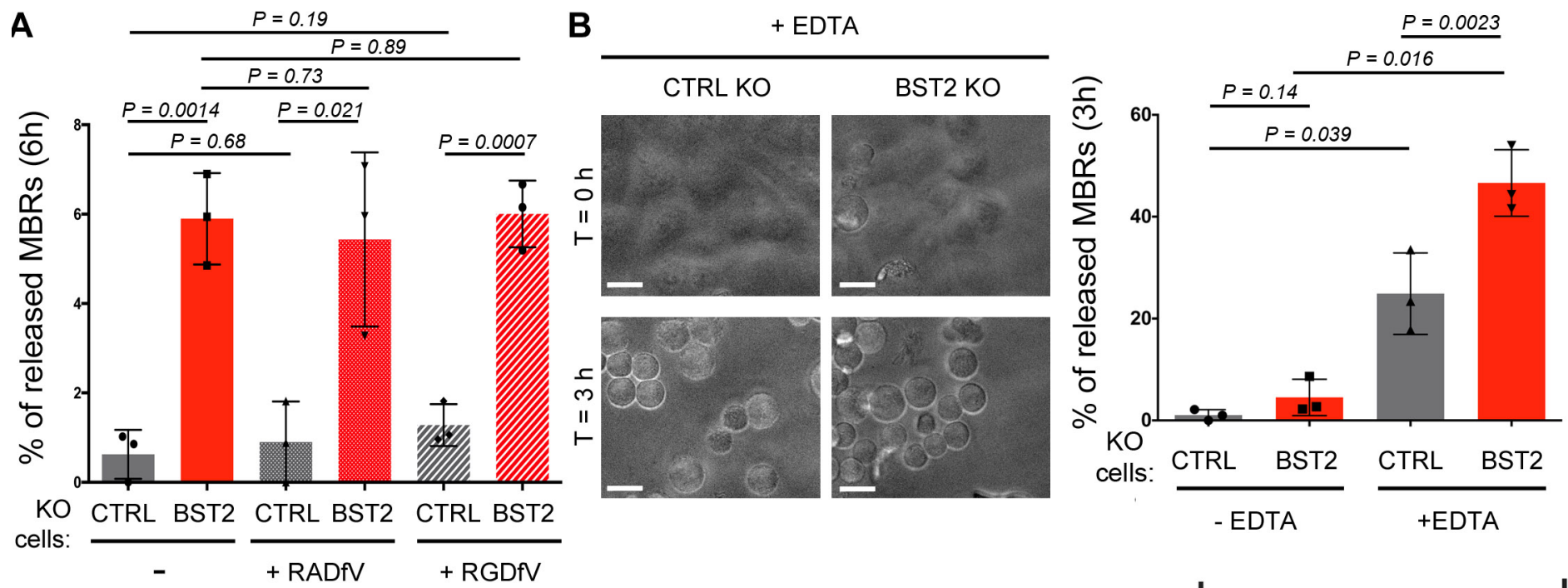

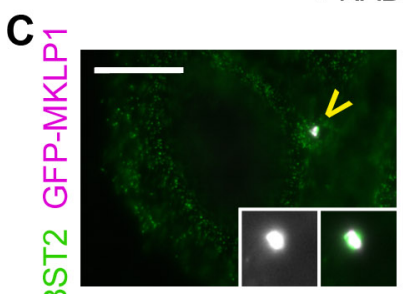

CTRL KO

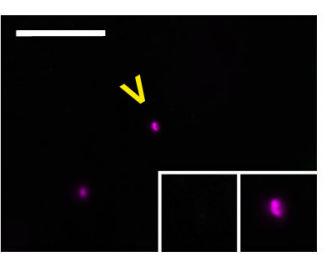

BST2 KO

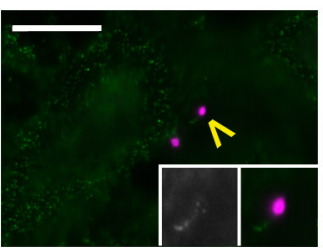

BST2 KO

+ BST2 C3A

D \% of MBRs at the cell surface

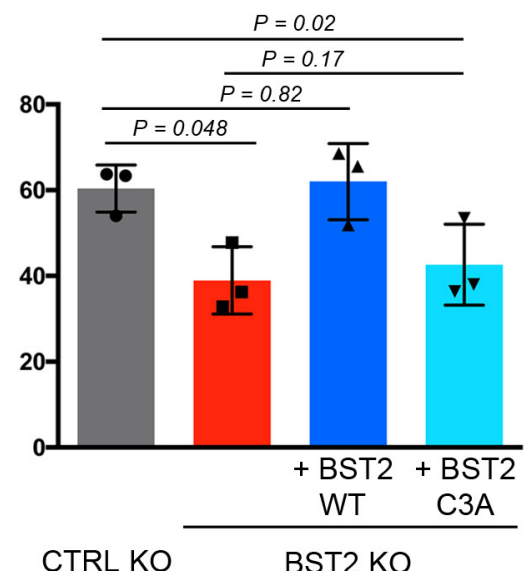

G

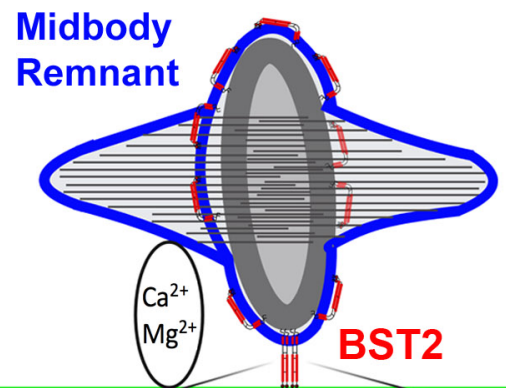

$\%$ of released MBRs

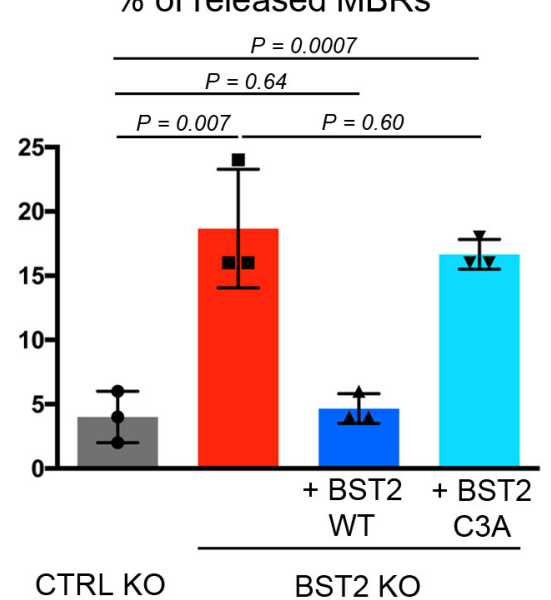

$\mathbf{F}$
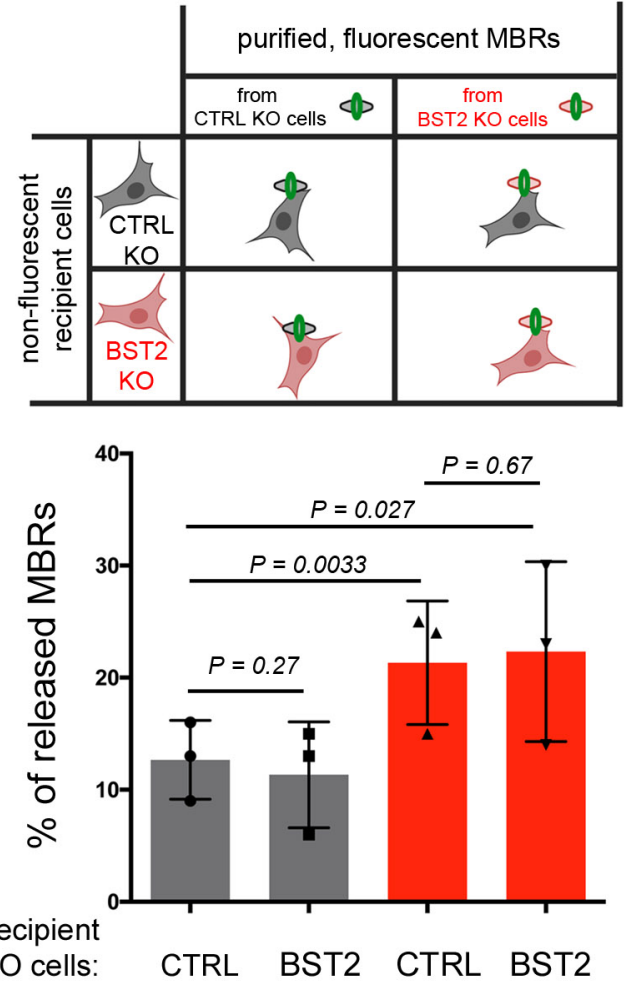

fluorescent MBRs from:

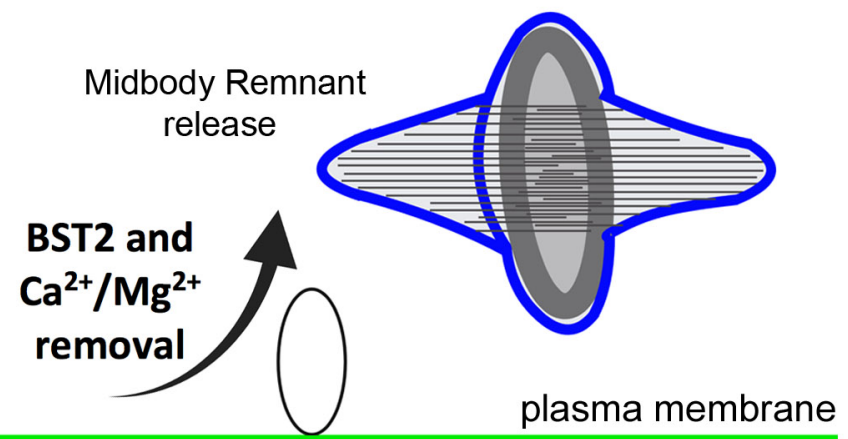

cell 
A

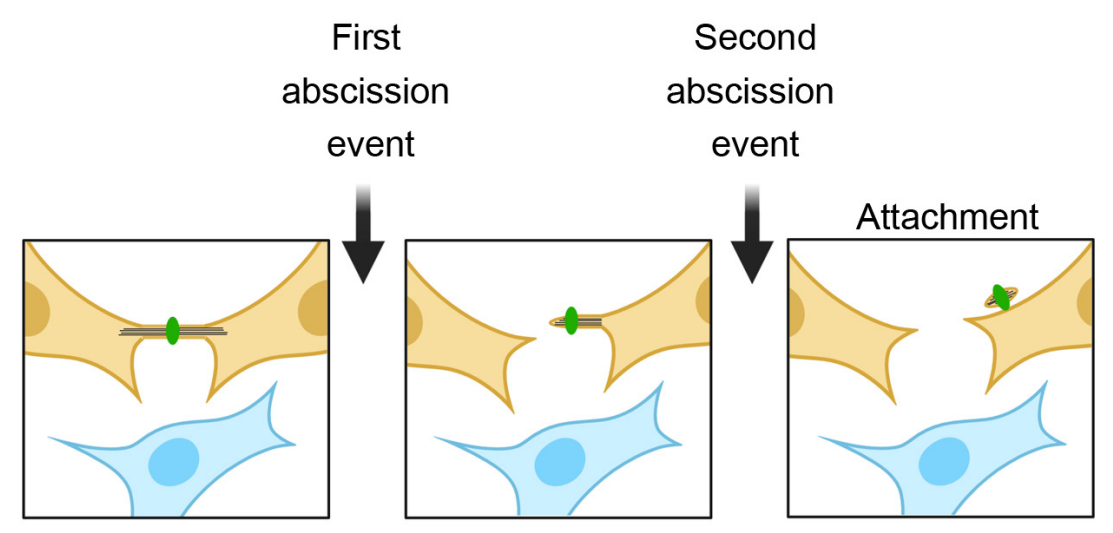

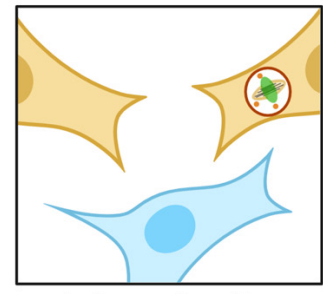

Internalization
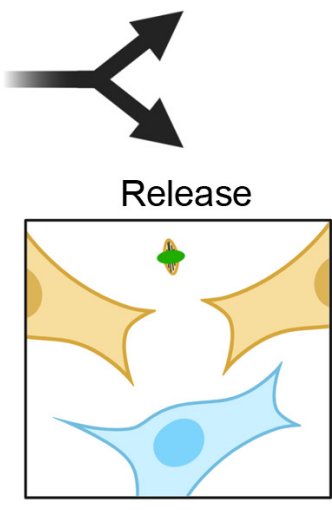

C

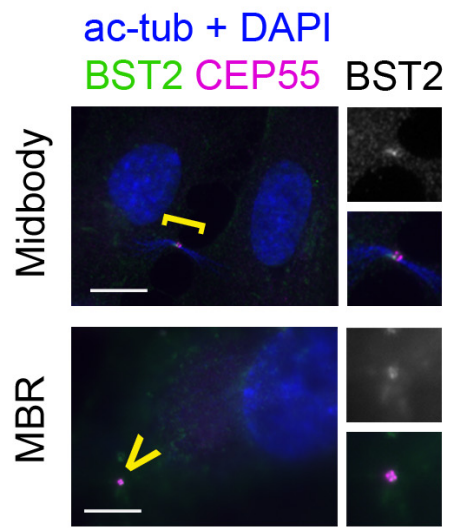

-IFNa

HUVEC

ac-tub + DAPI

BST2 CRIK BST2

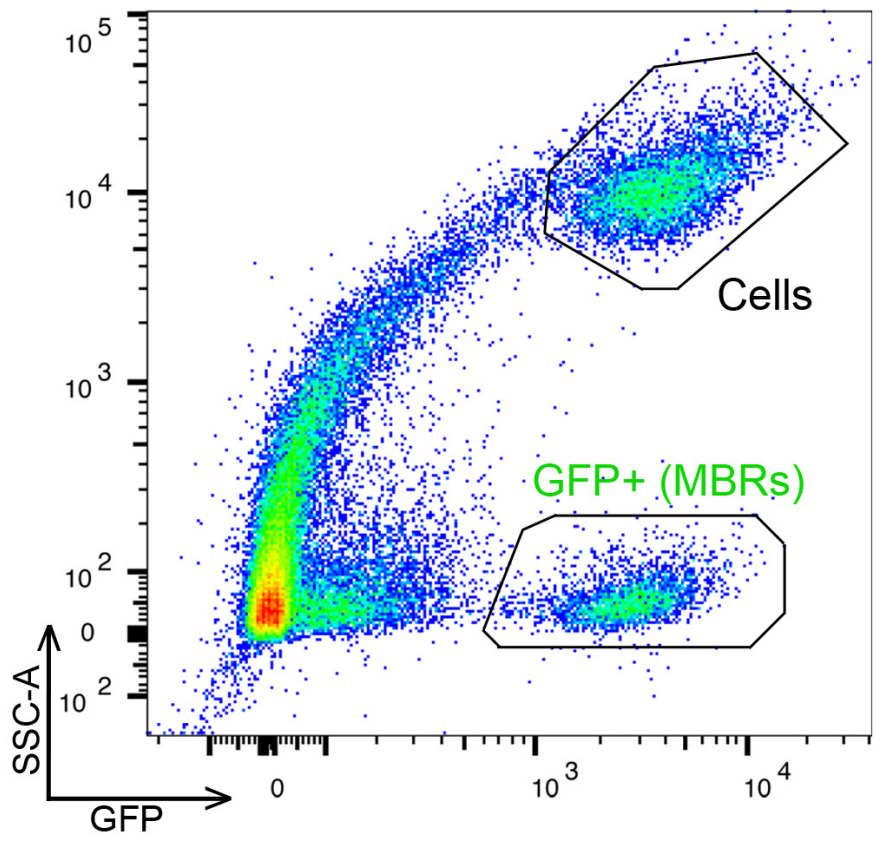

B

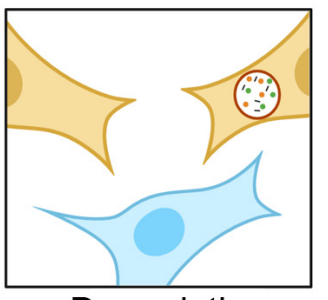

Degradation
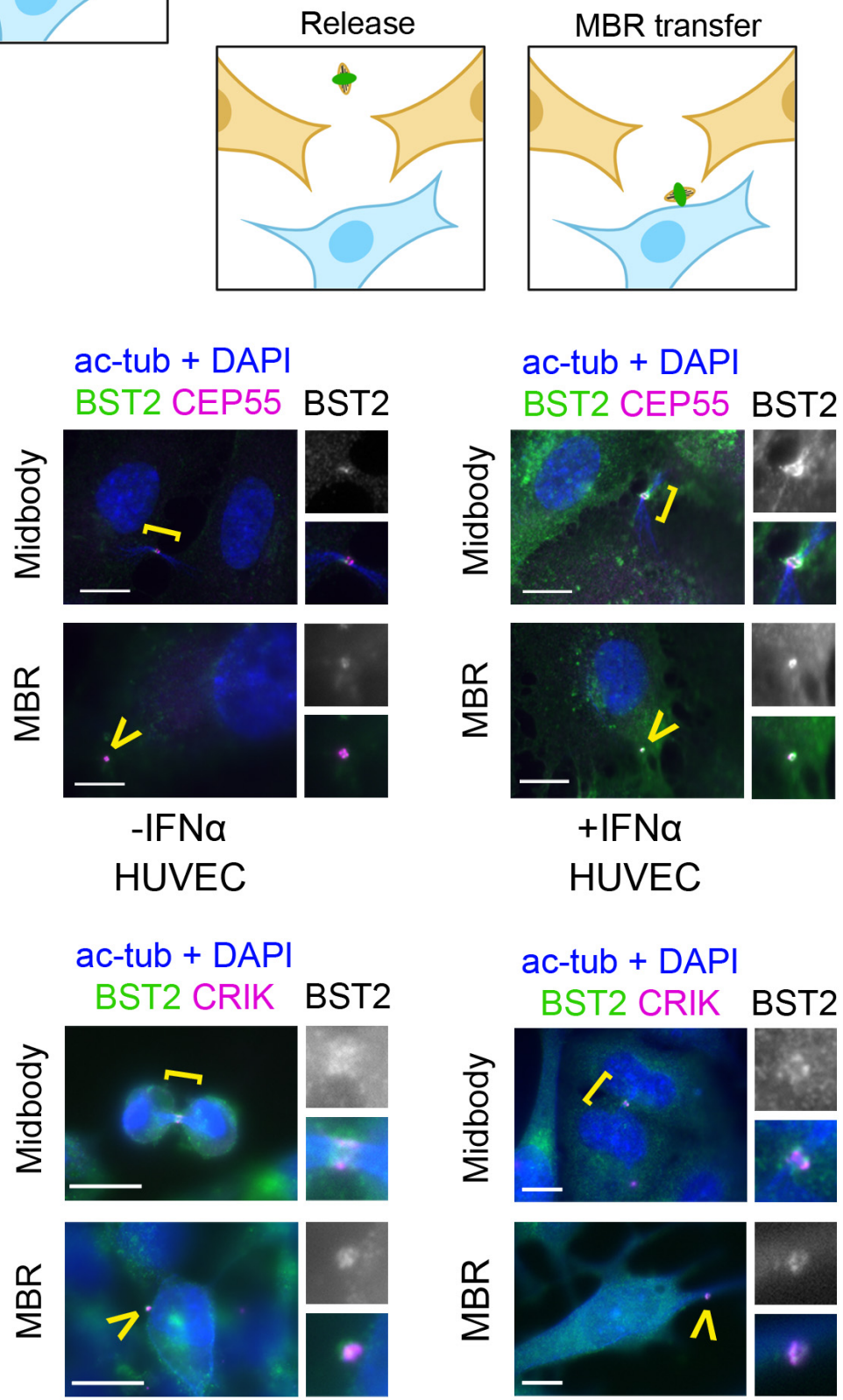

HepG2

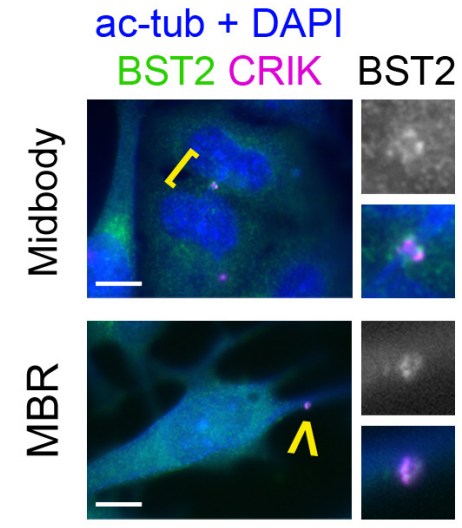

SK-MEL2

DAPI

BST2 CRIK BST2

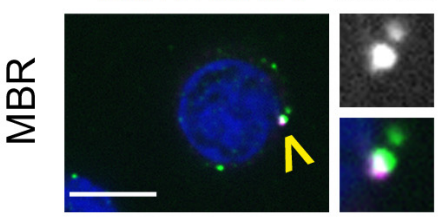

primary T lymphocyte 
Figure S1. BST2 is enriched at the midbody during cytokinesis and localizes to the surface of MBRs in a variety of cells. Related to Figure 1.

(A) Cartoon strip of MBR generation and fates. The post-mitotic MBR can be either inherited by a daughter cell, internalized and eventually degraded or released in the media and eventually transferred to a non-daughter cell.

(B) Representative pseudo-colored profile of flow cytometry sorting of GFP-MKLP1 MBRs (see reference ${ }^{35}$ for details). The window containing isolated, GFP-positive MBRs is indicated. GFPMKLP1 cells are clearly separated from the MBRs.

(C) Upper panels: Endogenous localization of BST2 (zoomed in grey) at the Midbody and MBR in HUVEC cells treated or not with IFNa, stained for acetylated-tubulin (ac-tub), DAPI and the midbody/MBR marker CEP55. Lower panels: Endogenous localization of BST2 (zoomed in grey) at the Midbody and MBR in the indicated cell lines and stained for acetylated-tubulin (ac-tub), DAPI and the midbody/MBR marker CRIK, as indicated. Brackets and arrowheads mark the bridge and the MBR, respectively. Scale bars $10 \mu \mathrm{m}$. 
A

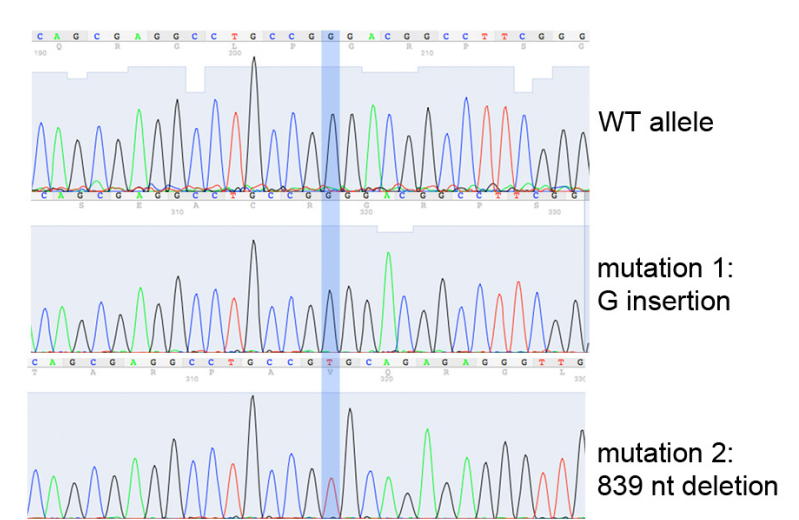

B Intracellular Transmembrane

tail domain

Coiled coiled domain

GPI

anchor Signal

site peptide

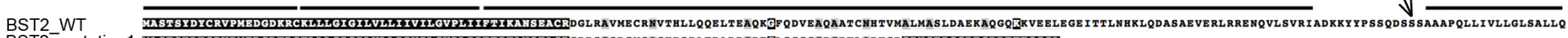

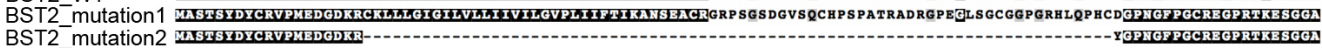

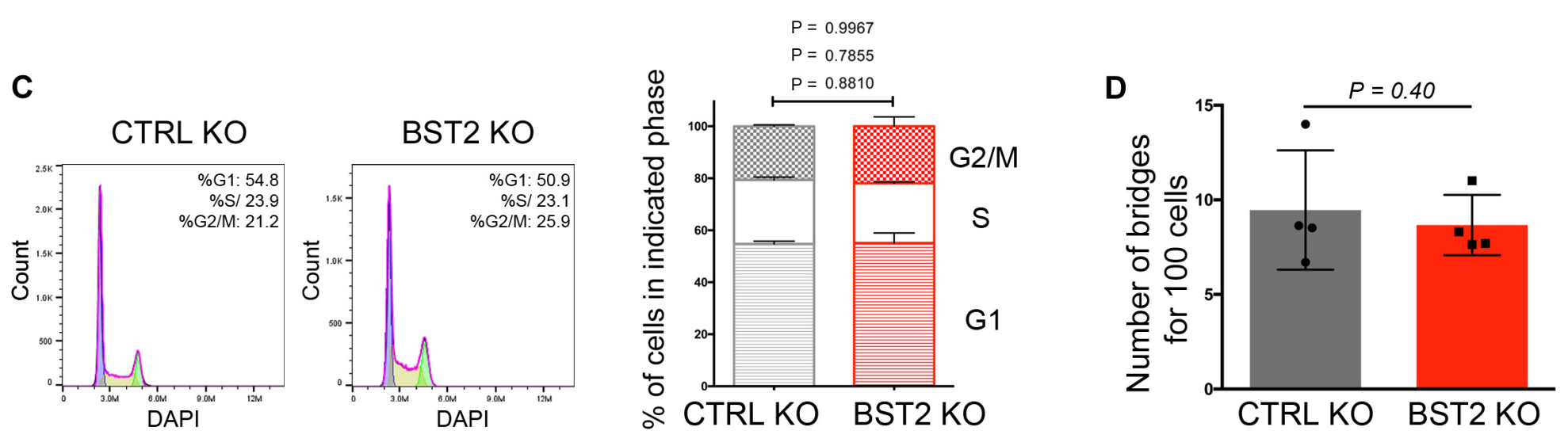

E

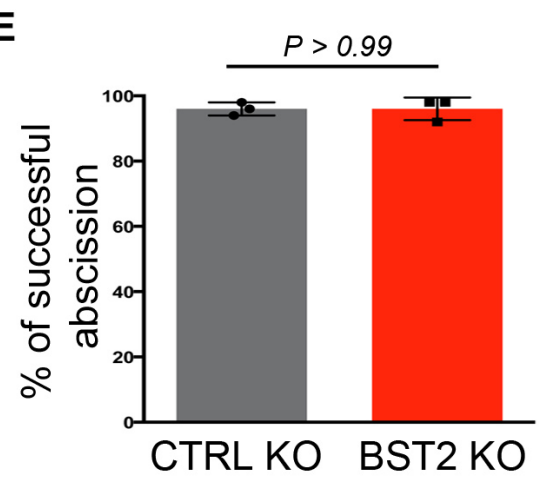

F

CD81

GFP-

CTRL KO

BST2 KO

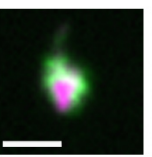

GFP-

MKLP1 CD81
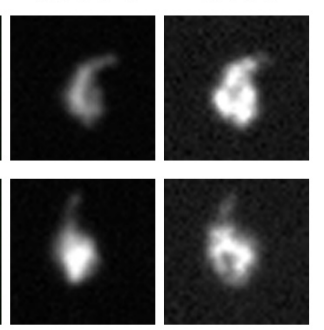

G

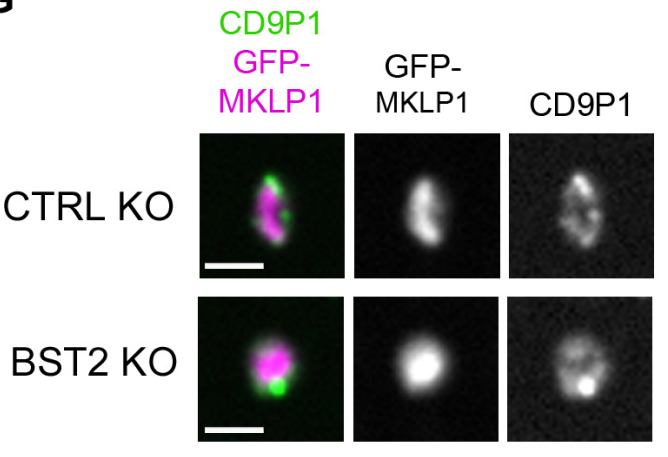

H

H GFP-MKLP1 CD9P1 DAPI

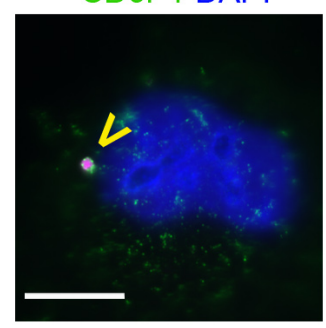

CTRL KO

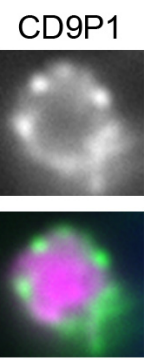

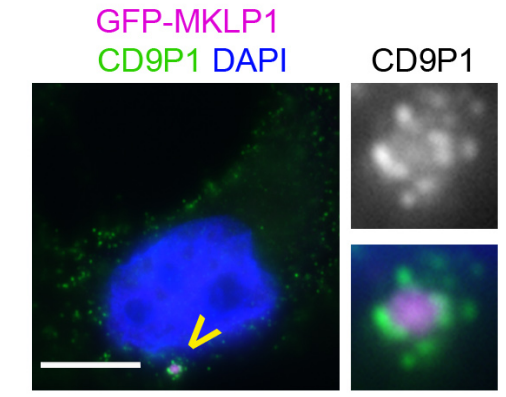

BST2 KO

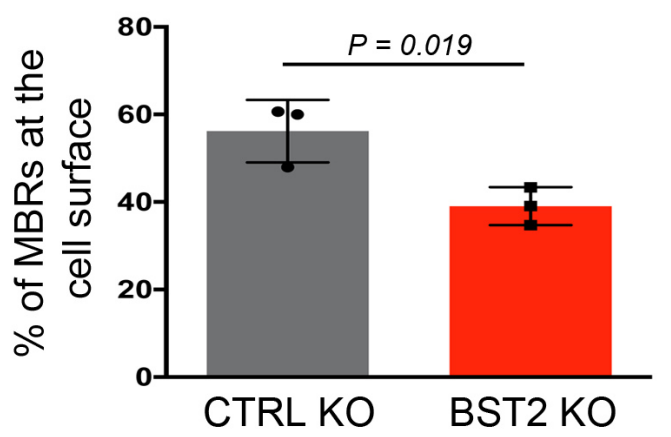


Figure S2. Characterization of BST2 KO cells. Related to Figure 2.

(A) Genomic sequences of BST2 at the target site of the CRISPR guide found in a CTRL KO clone (WT alleles) and in a BST2 KO clone (2 alleles mutated).

(B) BST2 coding sequences were determined by RT-PCR in CTRL KO and BST2 KO clones, then translated and aligned using Clustal W. The two different mutations found in the BST2 KO clone induced a frameshift leading to a premature STOP codon. Note that the BST2 signal peptide is lost in the BST2 KO clone for both alleles. Amino acids shaded in black and grey indicate identity and similarity, respectively. The different domains of BST2 are indicated above the sequence.

(C) Representative FACS analysis profile of the cell cycle in CTRL KO and BST2 KO GFP-MKLP1 Hela cells stained for DNA content with DAPI. The percentage of cells in G1, G2 and S-phase are indicated (mean+/-SD). 3 independent experiments, $\mathrm{N} \geq 10000$ cells analysed. One way ANOVA with adjusted P values (indicated respectively for G0/G1, S and $G 2$ above the different cell cycle phases).

(D) Quantification of intercellular bridges for 100 cells in asynchronous cell populations (mean \pm SD). 4 independent experiments, $n=117-126$ bridges. Paired two-sided Student's $t$-tests.

(E) Quantification of successful abscission by time-lapse phase-contrast microscopy in CTRL KO or BST2 KO GFP-MKLP1 Hela cells (mean \pm SD). $N=3$ independent experiments, $n=50$ cells per experiment. Paired two-sided Student's $t$-tests.

(F) and (G) Surface staining (without permeabilization) using antibodies against endogenous CD81 and CD9P1 on individual MBRs purified by flow-cytometry from CTRL KO and BST2 KO GFP-MKLP1 Hela cells. Scale bars $2 \mu \mathrm{m}$.

(H) CD9P1 surface staining of MBRs in CTRL KO and BST2 KO GFP-MKLP1 Hela cells. Arrowheads mark MBRs. Histogram: percentage of CD9P1-positive MBRs (mean \pm SD). $N=3$ independent experiments, $n=344-385$ MBRs. Paired two-sided Student's $t$ test. Scale bars: $10 \mu \mathrm{m}$. 
A
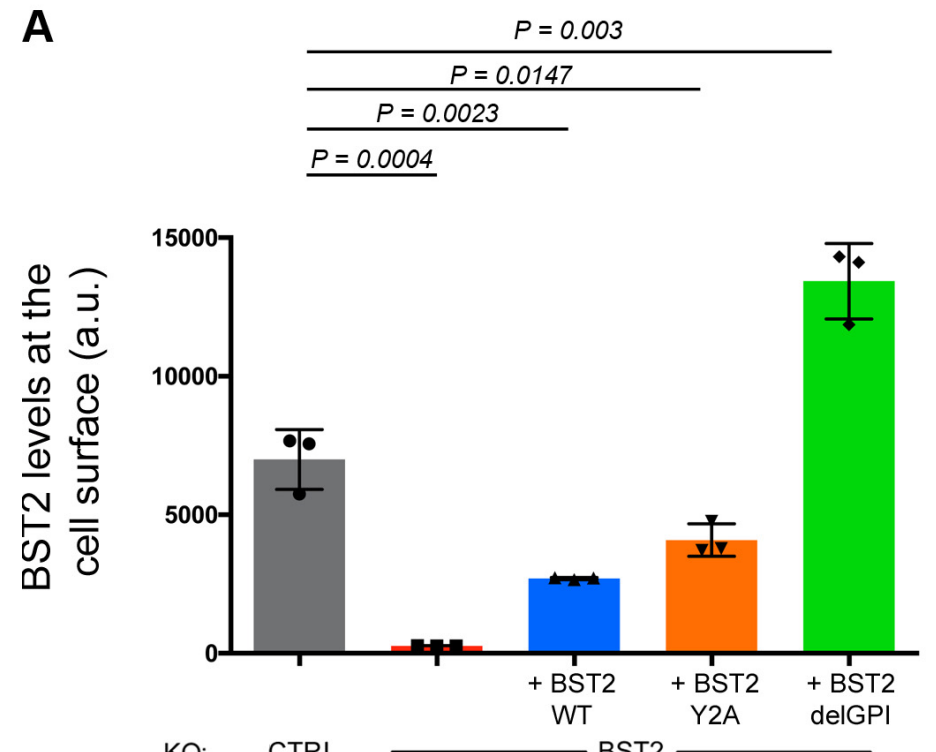

KO: CTRL

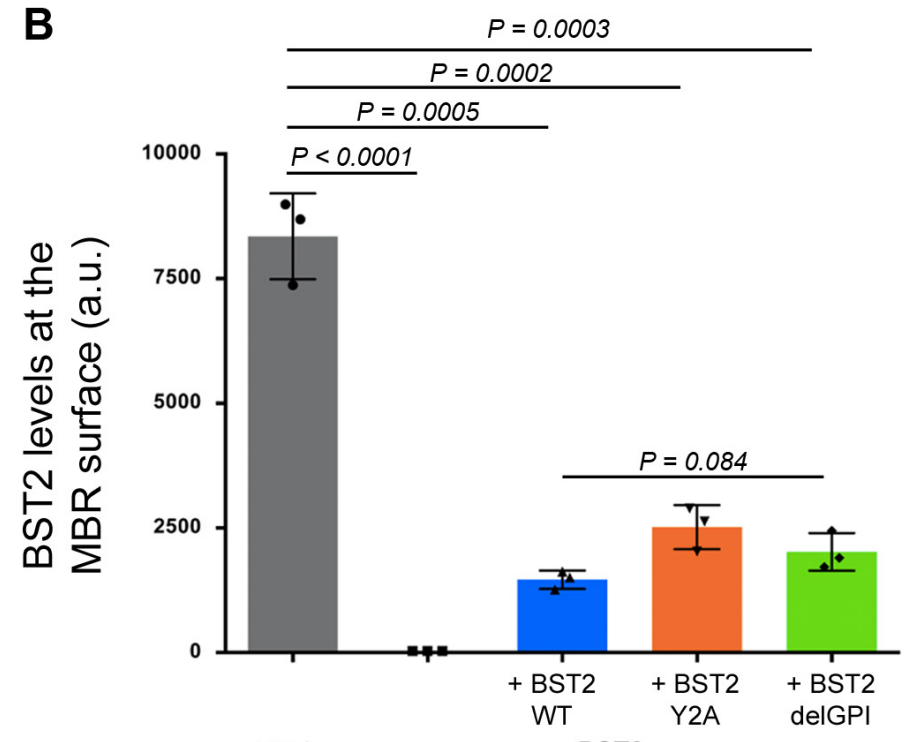

KO: CTRL
C

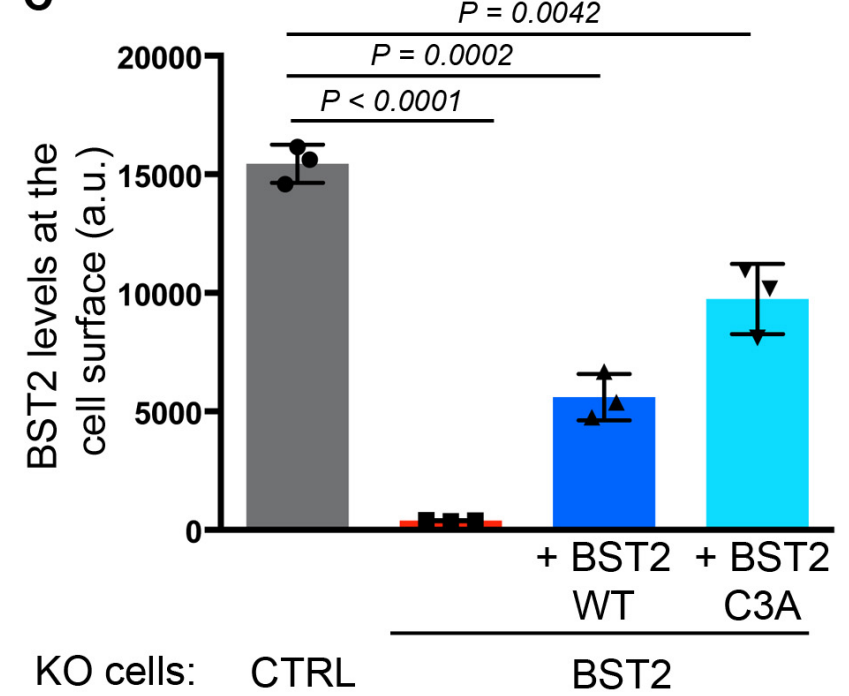

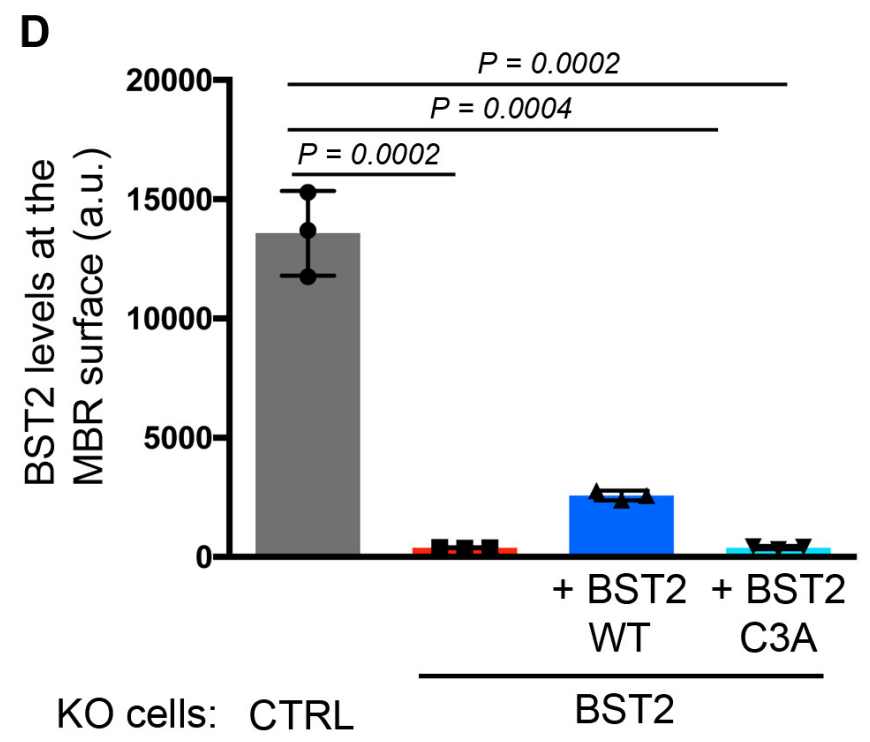


Figure S3. Characterization of BST2 levels in cells and MBRs in the different BST2 expressing cell lines. Related to Figures 3 and 4.

(A) Quantification of BST2 levels at the cell surface as assessed by FACS (a.u. arbitrary fluorescence units) in CTRL KO cells and BST2 KO cells re-expressing the indicated BST2 constructs. $N=3$ experiments, $n \geq 9000$ cells per experiment (mean \pm SD). Paired two-sided Student's $t$-tests.

(B) Quantification of BST2 MBR surface levels assessed by FACS (a.u. arbitrary fluorescence units) of the cells described in (A). $N=3$ experiments, $n \geq 1000$ MBRs (mean \pm SD). Paired two-sided Student's $t$-tests.

(C) Levels of BST2 at the cell surface were quantified by FACS (a.u. arbitrary units) in control KO cells and BST2 KO cells re-expressing or not BST2 WT or BST2 C3A. $N=3$ experiments, $n \geq$ 1000 MBRs (mean \pm SD). Paired two-sided Student's $t$-tests.

(D) Levels of BST2 at the MBR surface were quantified by FACS (a.u. arbitrary units) of the cells described in (C). $N=3$ experiments, $n \geq 9000$ cells per experiment (mean \pm SD). Paired twosided Student's $t$-tests. 
A

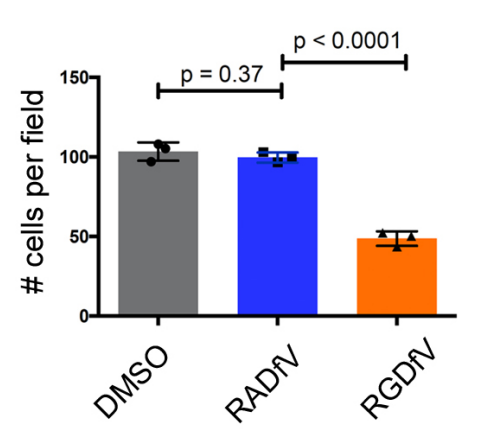

B

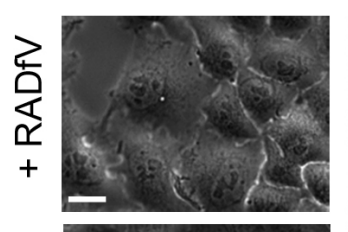

CTRL
KO
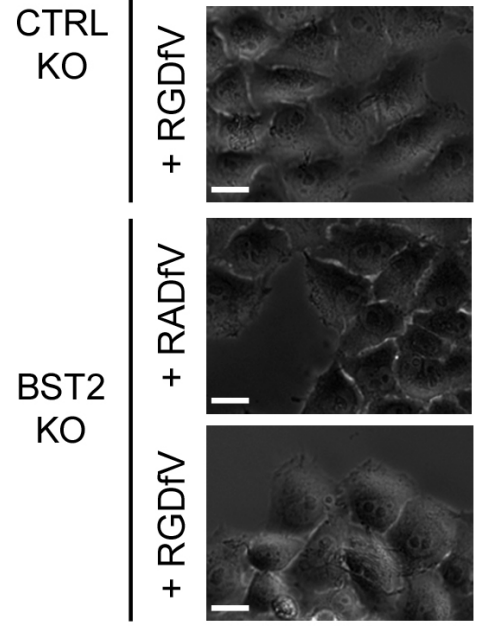

$\mathrm{T}=0 \mathrm{~h}$

C

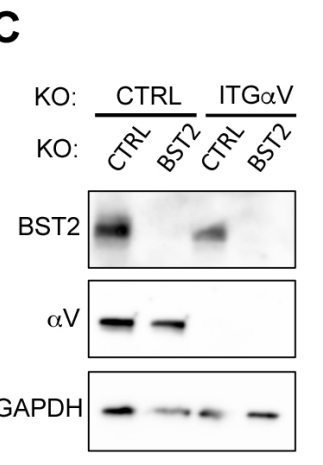

$\mathbf{F}$
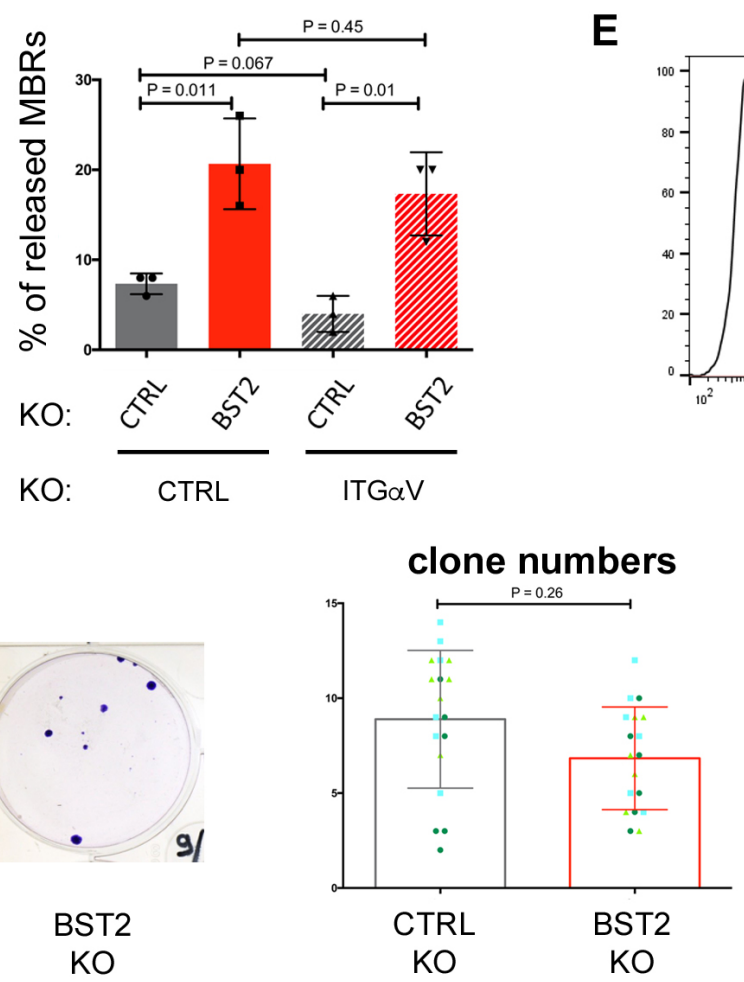

G
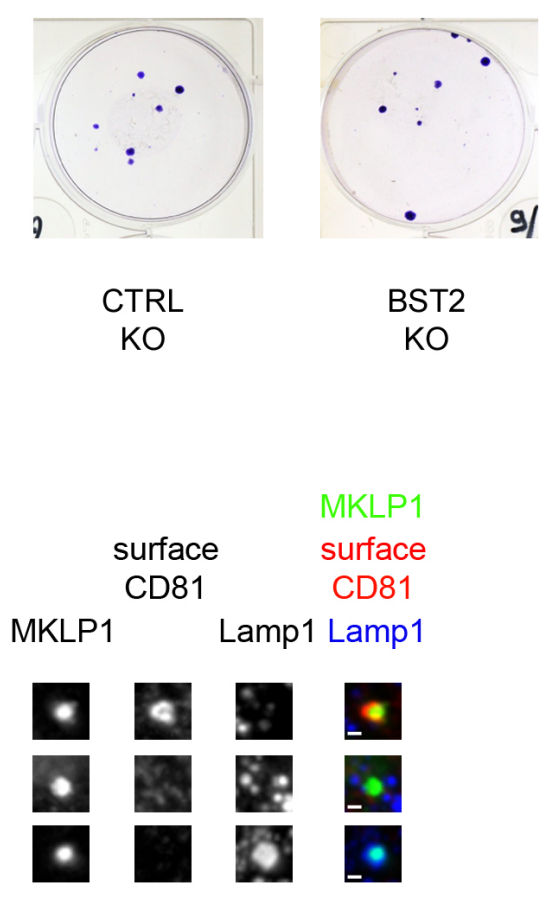

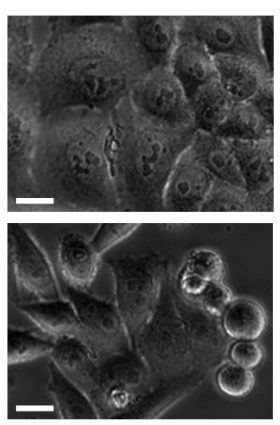

D + CTRL KO MBRs

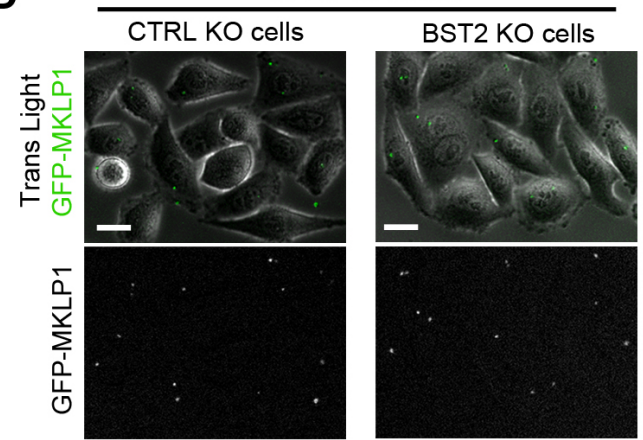

+ BST2 KO MBRs

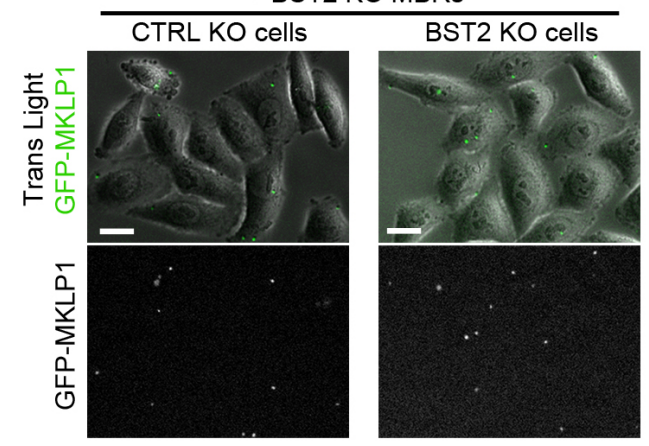

E
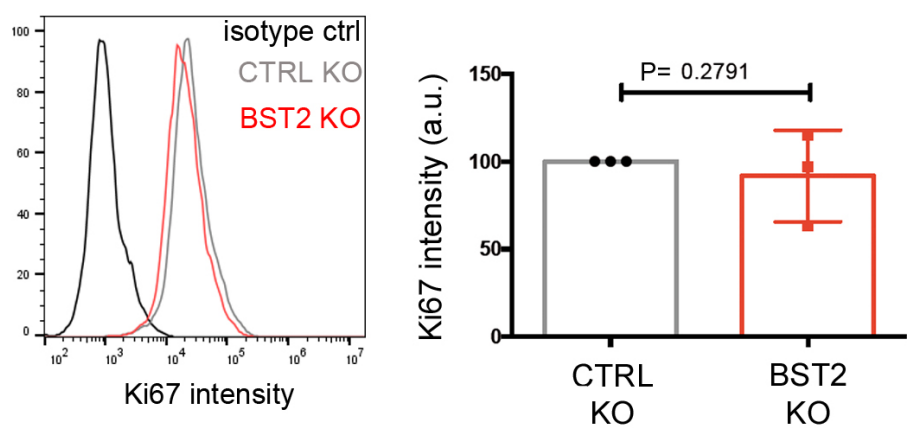
Figure S4. Effects of BST2 depletion on cellular proliferation and intracellular midbody degradation/turnover. Related to Figure 4.

(A) Detached HeLa cells were incubated with either DMEM, DMEM + RADfV or DMEM + RGDfV, and replated on fibronectin-coated coverslips. The number of re-adhered cells per field was quantified with DAPI staining. $N=3$ independent experiments, $n=38-113$ cells per experiment.

(B) Representative snapshots of CTRL KO and BST2 KO cells before and after $6 \mathrm{~h}$ treatment with either RADfV or RGDfV peptides. Scale bars $20 \mu \mathrm{m}$.

(C) Left panel: Lysates from CTRL KO or BST2 KO GFP-MKLP1 HeLa cells double knocked-out for ITG $\alpha$ V were analyzed by western blot with anti BST2 and anti ITG $\alpha$ V antibodies. Loading control: GAPDH. Right Panel: Percentage of MBRs released in the media determined by timelapse fluorescent microscopy, for each condition as indicated (mean \pm SD). $N=3$ independent experiments, $n=50$ MBRs per experiment. Paired two-sided Student's $t$-test.

(D) Representative snapshots of each combination described in Fig. 4E, right after incubation, as indicated. Scale bars $20 \mu \mathrm{m}$.

(E) Left: Representative profile of Ki67 labelled cells by FACS (a.u. arbitrary units) in CTRL KO (grey) and BST2 KO (red) GFP-MKLP1 HeLa cells with an APC-coupled anti-Ki67antibody. An APC-isotype control was used (black). Right: Mean intensity of Ki67. $N=3$ experiments, $n \geq$ 10000 cells acquired (mean \pm SD). Paired two-sided Student's $t$-test.

(F) Clonogenic assays: 100 CTRL KO or BST2 KO GFP-MKLP1 HeLa cells were plated by flow cytometry in 6-plicates and grown for 14 days. The cells were then fixed and stained with crystal violet. Left: representative pictures for CTRL and BST2 KO cells. Middle: quantification of the number of clones for 3 independent experiments, each in 6-plicates (mean \pm SD). Right: Image J Quantification of clone area (mean \pm SD) with each point representing one clone. $N=$ 3 independent experiments, $n=36-64$ clones per experiment. Paired two-sided Student's $t$ test.

(G) Left: GFP-MKLP1 HeLa cells were stained for CD81 at the cell surface (surface CD81), for total GFP-MKLP1 (MKLP1) and for total Lamp1 (Lamp1). This discriminated MBRs at the cell surface (CD81+ Lamp1-, upper row) from internal MBRs negative for Lamp1 (CD81- Lamp1-, middle row) or internal MBRs positive for Lamp1 (CD81- Lamp1+, lower row). Scale bars $1 \mu \mathrm{m}$. Right: quantification of the different MBR localizations in CTRL KO and BST2 KO cells re- 
expressing or not the different BST2 mutants, as indicated (mean \pm SD). $N=3$ independent experiments, $n=371-445$ MBRs. Paired two-sided Student's $t$-test. 
Control CRISPR guide

BST2 CRISPR guide

Integrin alpha $V$ CRISPR guide

Forward primer to amplify TOPO vector

Reverse primer to amplify TOPO vector

Forward primer to amplify BST2 RT product

Reverse primer to amplify BST2 RT product

BST2 mutation Y6A Forward

BST2 mutation Y8A Forward

BST2 mutation C53A Forward

BST2 mutation C63A Forward

BST2 mutation C91A Forward

BST2 mutation S161STOP Forward sequence 5'-> 3'

AAGATGAAAGGAAAGGCGTT

GCCGGACGGCCTTCGGGCA

GTGACTGGTCTTCTACCCGC

GCCCGTAGAAGATTCCAGCA

GGAAGCCATTAGGGCCATCTAA

GCCCGTAGAAGATTCCAGCA

TGTTCAAGCGAAAAGCCGAG

GGCATCTACTTCGGCTGACTATTGCAGAG

ACTTCGGCTGACTATTGCAGAGTGCCCA

CAGCGAGGCCGCCCGGGACGGCC

CGGGCAGTGATGGAGGCTCGCAATGTACCCA

CACAGTGTGGTTGGCGGTGGCGGCCTGG

GGACTCCAGCTAGGCTGCGGCGC

Table S1. Oligonucleotides used in this study. Related to Figures 1, 2, 3 and 4. 


\section{KEY RESOURCES TABLE}

\begin{tabular}{|c|c|c|}
\hline REAGENT or RESOURCE & SOURCE & IDENTIFIER \\
\hline \multicolumn{3}{|l|}{ Antibodies } \\
\hline Rabbit polyclonal anti-BST2 & Proteintech & $\begin{array}{l}\text { Cat\# 13560-1-AP; } \\
\text { RRID: AB_2067220 }\end{array}$ \\
\hline Rabbit polyclonal anti-integrin alpha $\mathrm{V}$ & Proteintech & $\begin{array}{l}\text { Cat\# 27096-1-AP; } \\
\text { RRID: AB_2880753 }\end{array}$ \\
\hline Mouse monoclonal anti-Cep55 & $\begin{array}{l}\text { Santa Cruz } \\
\text { Biotechnology }\end{array}$ & $\begin{array}{l}\text { Cat\# sc-374051; } \\
\text { RRID: AB_10917564 }\end{array}$ \\
\hline Mouse monoclonal anti-CRIK & BD Biosciences & $\begin{array}{l}\text { Cat\# 611376; RRID: } \\
\text { AB_398898 }\end{array}$ \\
\hline Mouse monoclonal anti-CD81 & $\begin{array}{l}\text { Kind gift from Dr. E. } \\
\text { Rubinstein }\end{array}$ & N/A \\
\hline Mouse monoclonal anti-CD9P1 & $\begin{array}{l}\text { Kind gift from Dr. E. } \\
\text { Rubinstein }\end{array}$ & $\mathrm{N} / \mathrm{A}$ \\
\hline Rabbit polyclonal anti-Lamp1 & Abcam & $\begin{array}{l}\text { Cat\# ab24170; } \\
\text { RRID: AB_775978 }\end{array}$ \\
\hline Chicken polyclonal anti-GFP & Abcam & $\begin{array}{l}\text { Cat\# ab13970; } \\
\text { RRID: AB_300798 }\end{array}$ \\
\hline Human monoclonal anti-acetylated tubulin & $\begin{array}{l}\text { Institut Curie, Paris } \\
\text { France }\end{array}$ & Cat\# A-R-H\#39 \\
\hline Mouse monoclonal anti-GAPDH & Proteintech & $\begin{array}{l}\text { Cat\# 60004-1-Ig; } \\
\text { RRID: AB 2107436 }\end{array}$ \\
\hline APC mouse monoclonal isotype control & BioLegend & $\begin{array}{l}\text { Cat\# } 400121 \text {; RRID: } \\
\text { AB_326443 }\end{array}$ \\
\hline APC human monoclonal anti-BST2 & BioLegend & $\begin{array}{l}\text { Cat\# 348410; RRID: } \\
\text { AB_2067121 }\end{array}$ \\
\hline \multicolumn{3}{|l|}{ Bacterial and Virus Strains } \\
\hline E. coli DH5 $\alpha$ & Gibco & Cat\# 18265017 \\
\hline \multicolumn{3}{|c|}{ Chemicals, Peptides, and Recombinant Proteins } \\
\hline Human TNF $\alpha$ & Thermofisher & Cat\# PHC3015 \\
\hline 123count ebeads & invitrogen & Cat\# 15526296 \\
\hline RADfV control peptide & Enzo life Sciences & Cat\# BML-AM101 \\
\hline RGDfV & Enzo life Sciences & Cat\# BML-AM100 \\
\hline SiR-tubulin & Tebu-bio & Cat\# SC002 \\
\hline \multicolumn{3}{|l|}{ Critical Commercial Assays } \\
\hline PNGase F & New England Biolabs & Cat\# P0704S \\
\hline ExceLenti LTX Lentivirus Packaging Mix & Oxford genetics & Cat\# EXL10 \\
\hline TOPO 2.1 TA cloning kit & Thermofisher & Cat\# 45-0641 \\
\hline \multicolumn{3}{|l|}{ Experimental Models: Cell Lines } \\
\hline Human: HeLa cells & ATCC & CCL-2 \\
\hline Human: HeLa cells & $\begin{array}{l}\text { Kyoto, Kind gift from } \\
\text { Dr. M.Piel }\end{array}$ & N/A \\
\hline Human: GFP-MKLP1 HeLa cells & Ref. $^{45}$ & $\mathrm{~N} / \mathrm{A}$ \\
\hline Human: HEK293 & ATCC & CRL-1573 \\
\hline Human: HEK293FT & Thermofisher & Cat\# R70007 \\
\hline Human: SK-MEL2 Dynamin-GFP & $\begin{array}{l}\text { Kind gift from Dr. N. } \\
\text { Sauvonnet. Ref. }{ }^{64}\end{array}$ & $\mathrm{~N} / \mathrm{A}$ \\
\hline Human: HepG2 & Ref. $^{65}$ & $\mathrm{~N} / \mathrm{A}$ \\
\hline Human: Caco-2 & $\begin{array}{l}\text { Kind gift from Dr. M. } \\
\text { Lecuit }\end{array}$ & HTB-37 \\
\hline Human: HUVEC & $\begin{array}{l}\text { Kind gift from Dr. E. } \\
\text { Lemichez }\end{array}$ & $\mathrm{N} / \mathrm{A}$ \\
\hline
\end{tabular}




\begin{tabular}{|c|c|c|}
\hline Human: primary T lymphocytes & $\begin{array}{l}\text { Kind gift from Dr. N. } \\
\text { Casartelli and Dr. O. } \\
\text { Schwartz }\end{array}$ & $\mathrm{N} / \mathrm{A}$ \\
\hline \multicolumn{3}{|l|}{ Oligonucleotides } \\
\hline $\mathrm{N} / \mathrm{A}$ & $\begin{array}{l}\text { See Table S1 for } \\
\text { oligonucleotides }\end{array}$ & $\mathrm{N} / \mathrm{A}$ \\
\hline \multicolumn{3}{|l|}{ Recombinant DNA } \\
\hline BST2 WT pcDNA3.1 & This paper & $\mathrm{N} / \mathrm{A}$ \\
\hline BST2 GFP & This paper & $\mathrm{N} / \mathrm{A}$ \\
\hline pLenti4to pDEST V5 Nter & Thermofisher & Cat\# V49810 \\
\hline pSpCas9(BB)-2A-Puro (PX459) V2.0 & Addgene & Plasmid \# 62988 \\
\hline \multicolumn{3}{|l|}{ Software and Algorithms } \\
\hline Fiji (ImageJ) & ImageJ & $\begin{array}{l}\text { https://imagej.nih.go } \\
\text { v/ij/ }\end{array}$ \\
\hline Icy & Icy & $\begin{array}{l}\text { http://icy.bioimagean } \\
\text { alysis.org/ }\end{array}$ \\
\hline Graphpad Prism & Graphpad & $\begin{array}{l}\text { https://www.graphpa } \\
\text { d.com/scientific- } \\
\text { software/prism/ }\end{array}$ \\
\hline Metamorph & Molecular Devices & $\begin{array}{l}\text { https://www.molecul } \\
\text { ardevices.com/ } \\
\text { products/cellular- } \\
\text { imaging-systems/ } \\
\text { acquisition-and- } \\
\text { analysis-software/ } \\
\text { metamorph- } \\
\text { microscopy }\end{array}$ \\
\hline Flowjo & Flowjo & $\begin{array}{l}\text { https://www.flowjo.co } \\
\mathrm{m} /\end{array}$ \\
\hline
\end{tabular}

